\title{
GEODINÂMICA DOS CAMPOS DE DUNAS MÓVEIS DE JERICOACOARA/CE-BR
}

\author{
geodynamics aspects of the coastal sand dunes of Jericoacoara National Park, Ceará/Brazil
}

\author{
Antônio Jeovah Andrade de Meireles*
}

\begin{abstract}
Resumo
A planície costeira de Jericoacoara foi caracterizada de acordo com os componentes morfológicos associados aos campos de dunas e ecossistema manguezal. A composição morfológica atual da planície e a dinâmica de migração das dunas móveis foram definidas através de imagens de satélite dos últimos 35 anos (1975 a 2010$)$ e mapas geoambientais. Foi possível determinar um deslocamento médio das dunas de 16,5m/ano - entre 1975 e 2005 a média foi de $12,4 \mathrm{~m}$ e, para os últimos 5 anos foi $20,6 \mathrm{~m}$ - com diâmetro médio de $3.359,0 \mathrm{~m}$ e área em torno de $332.695,0 \mathrm{~m} 2$ (alterações relacionadas com a sazonalidade climática e interferências humanas). Observou-se nas dumas mais interiores um aumento na velocidade de migração para os últimos 5 anos - a duna Arraia passou de velocidade média de 10m (entre 1975 e 2005) para 30m nos últimos 5 anos. Para as que se aproximaram da praia a velocidade aumentou de 10 a 30\%: dinâmica regida pela achegada às ondas e à zona de sombra provocada pelo serrote de Jericoacoara. A flecha de areia diante do manguezal do rio Guriú avançou $1.060 \mathrm{~m}$ na direção da margem direita do rio, de acordo com chegada de sedimentos proveniente da deriva litorânea. Entretanto, com uma erosão total de $50 \mathrm{~m}$, continente adentro, para os últimos 35 anos. A evolução espaçotemporal revelou incremento na migração das dunas e erosão costeira.
\end{abstract}

Palavras-chave: Campo de dunas móveis, evolução espaçotemporal, indicadores de mudanças climáticas e do nível relativo do mar, impactos ambientais.

\begin{abstract}
The coastal plain Jericoacoara was characterized by the components defined as fields of dunes and mangrove ecosystem. The current morphological composition of the plain and the dynamics of migration of dunes have been identified through satellite imagery of the last 35 years (1975 to 2010) and geo-environmental maps. It was possible to determine an average displacement of the dunes of $16.5 \mathrm{~m} /$ year - between 1975 and 2005 the average was $12.4 \mathrm{~m}$, and for the last 5 years was $20.6 \mathrm{~m}$ - with an average diameter of 3359.0 $\mathrm{m}$ and the area around $332,695.0 \mathrm{~m} 2$ (changes related to climatic seasonality and interference human). We observe in the dunes further inland migration speed increased in the last five years - the dune fish increased its average speed of $10 \mathrm{~m}$ (between 1975 and 2005) to 30m in the last 5 years (doubled). The proximity to the beach with the speed increased from 10 to $30 \%$, probably governed by dynamic waves and the shadow area caused by the saw of Jericoacoara. The arrow on the sand of the river mangrove Guriú $1.060 \mathrm{~m}$ moved toward the right bank of the river, according to the aprotic sediment from the longshore drift, however, with erosion of $50 \mathrm{~m}$ for the last 35 years. The evolution espaçotemporal revealed an increase in the migration of dunes and coastal erosion.
\end{abstract}

Key words: Mobile dune field, geomorphological evolution, indicators of climate change and relative sea level and environmental impacts.

\section{Resumen}

La llanura costera Jericoacoara se ha caracterizado por los campos de dunas y el ecosistema manglar. La actual composición morfológica de la llanura y la dinámica de migración de las dunas han sido identificados a través de imágenes satelitales de los últimos 35 años (1975 a 2010) y los mapas geo-ambientales. Fue posible determinar un desplazamiento medio de las dunas de $16,5 \mathrm{~m} /$ año - entre 1975 y 2005 el promedio fue de $12,4 \mathrm{~m}$, y para los últimos 5 años fue de $20,6 \mathrm{~m}$ - con un diámetro promedio de 3359,0 metros y el área alrededor de $332,695.0 \mathrm{~m} 2$ (cambios relacionados con el clima estacional y la interferencia humana). Se ha detectado, en las dunas hacia el interior, aumento en la velocidad de la migración en los últimos cinco años la duna Arraia aumentó su velocidad media de 10 m (entre 1975 y 2005) para 30m en los últimos 5 años (se ha triplicado). La proximidad a la playa, la velocidad ha aumentado alrededor de 10 a 30\%, probablemente gobernada por la dinámica del oleaje y el área de sombra (interferéncia en la velocidad e dirección de los vientos) generada por la sierra de Jericoacoara. La flecha de arena por delante del manglar se ha acrecido $1.060 \mathrm{~m}$ y se dirigió hacia la orilla derecha del río, de acuerdo con el volumen de arena aportado por las dunas; sin embargo, con una erosión costera de 50 metros en los últimos 35 años. La evolución de la llanura ha revelado un incremento en la migración de las dunas y en la erosión de la franja litoral.

Palabras clave: Campo de dunas móviles, evolución geomorfológica, indicadores del cambio climático y del nivel del mar y los impactos ambientales.

(*) Bolsista Produtividade CNPq, Prof. Dr. da Pós Graduação em Geografia Universidade Federal do Ceará - Campus do Pici, Bloco 911, CEP: 60.455-760, Fortaleza (CE) - Brasill, Tél./Fax.: (+ 55 85) 3366-9855 / 3366.9864 - meireles@ufc.br 


\section{INTRODUÇÃO}

A planície costeira de Jericoacoara está situada na costa oeste do estado do Ceará, no litoral dos municípios de Jijoca de Jericoacoara, Cruz e Camocim, a aproximadamente $300 \mathrm{~km}$ de Fortaleza. A área de estudo abrange grande parte da Unidade de Conservação (UC) de Proteção Integral - Parque Nacional de Jericoacoara (Parna Jericoacoara) - instituída em 4 de fevereiro de 2002 com uma área de 8.416,08ha. Para se alcançar o Parna Jericoacoara, a partir de Fortaleza, o acesso pode ser realizado pelas rodovias federais BR 116 e BR 220 e rodovia estadual CE-85 até Itapipoca e, em seguida, pela CE-179 até o município de Jijoca de Jericoacoara. Para chegar à vila de Jericoacoara, localizada no interior do Parque, o acesso dá-se por trilhas não-pavimentadas e utilizando preferencialmente veículos de tração e buguies que adentram em extenso campo de dunas e lagoas costeiras (Figuras 1 e 2).

Para iniciar os estudos com o objetivo de elaborar modelo de migração do campo de dunas barcanas e elaborar banco de dados para o monitoramento da dinâmica morfológica da planície costeira de Jericoacoara, foi realizado mapeamento que definiu morfologias originadas por processos geoambientais desencadeados pelas mudanças do nível relativo do mar e climáticas durante o Quaternário. Foram identificadas gerações de dunas, lagunas e lagoas costeiras, estuários, mangue e paleomangue (praias lamosas), canais de marés, terraços marinhos, promontórios, plataformas de abrasão, tabuleiro pré-litorâneo e praias arenosas e rochosas, que indicaram eventos eustáticos, evidenciando relações continente-oceano-atmosfera na formação da planície costeira. Aliado aos processos dinâmicos (transporte de sedimentos pelos ventos, hidrodinâmica estuarina, alternâncias sazonais do freático, deslizamentos e escorregamentos das encostas do serrote de Jericoacoara, ondas e marés), foram brevemente analisadas as atividades socioeconômicas e culturais relacionadas com o turismo, pesca e agricultura de subsistência. Estes dados foram utilizados para evidenciar possibilidade de interferências humanas na velocidade e direção de migração das dunas.

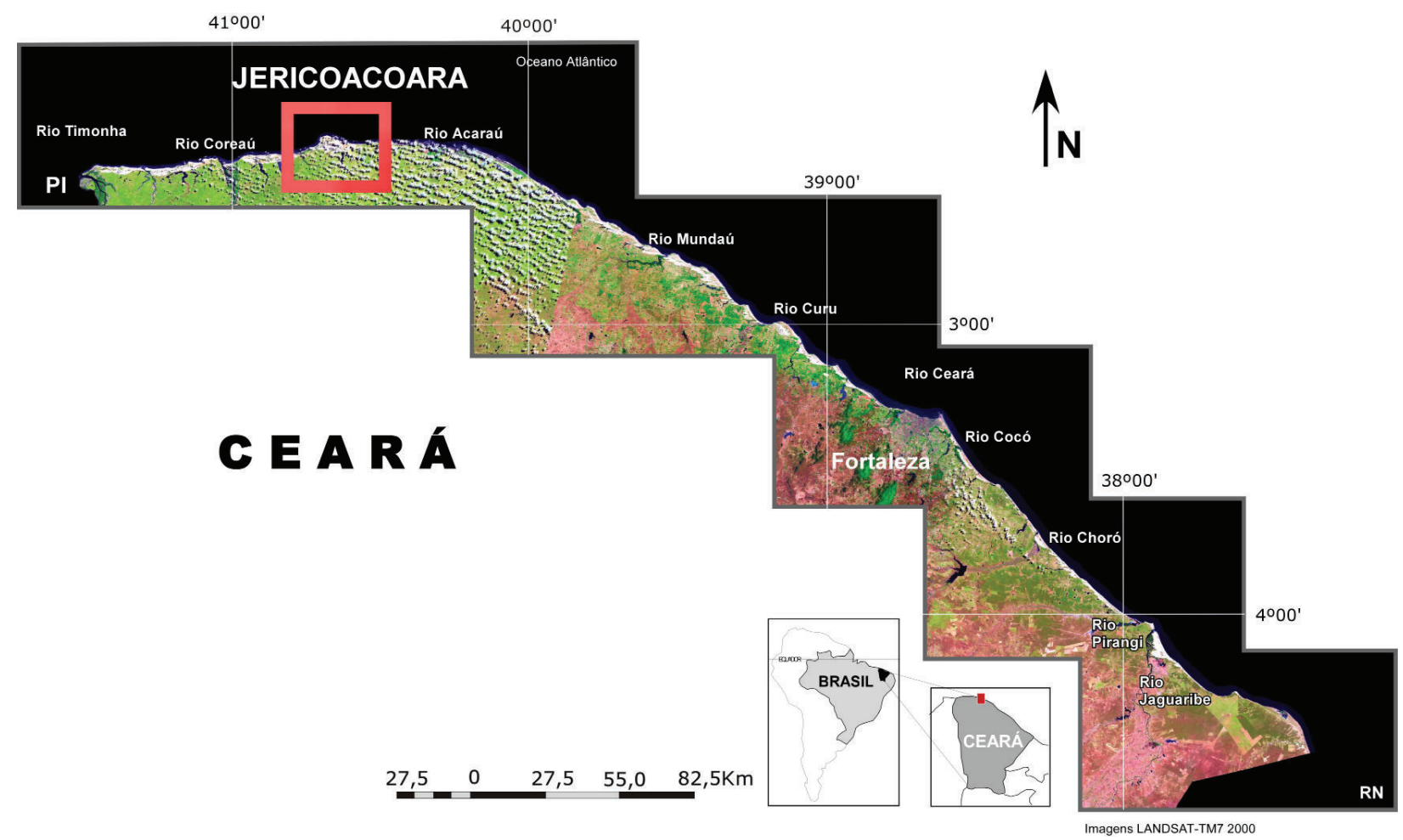

Figura 1 - Localização regional da área de estudo.

Foi possível identificar três gerações de dunas ao longo da planície costeira de Jericoacoara:

i. $1^{\text {a }}$ geração - formada por dunas fixas (vegetação arbórea com transição para o tabuleiro pré-litorâneo na borda sul do campo), dos tipos parabólicas e, secundariamente, dômicas, 
localizadas mais no interior da planície. Em setores próximos às dunas de segunda geração, estão sendo soterradas pelas dunas móveis. São mais elevadas que as outras gerações e possivelmente aturam como barriras eólicas para a migração das dunas que se dirigem para setores $\mathrm{SE} / \mathrm{SW}$ da planície costeira;

ii. $2^{\mathrm{a}}$ geração, composta pelo conjunto de dunas móveis dos tipos barcanas e barcanóides. Está relacionado a pulsos de sedimentos provavelmente originados por alterações de alta frequência do nível relativo do mar (MEIRELES et al., 2002). Estas dunas estão associadas com as foram espaçotemporais e direcionais que definem intervalos de migração e direção preferencial de deslocamento e,

iii. $3^{\text {a }}$ Geração, representada por dunas móveis atuais do tipo longitudinais, dispostas sobre a zona de berma atual (com ocorrência de barcanas de pequeno porte, entre 3 a $5 \mathrm{~m}$ de altura, sobre o extirâncio superior). Está associada às morfologias produzidas pelo imediato transporte de areia da faixa de praia.

Para evidenciar a dinâmica evolutiva do campo de dunas do Parna Jericoacoara foram definidas as dunas móveis do tipo barcanas que migram preferencialmente de leste para oeste na direção da faixa de praia (Figura 2). As dunas móveis, quando relacionadas aos promontórios, os sedimentos foram novamente lançados para a praia e de acordo com a direção preferencial dos ventos. Ao longo da planície costeira de Jericoacoara, verificou-se que as dunas móveis alcançam a faixa de praia e, durante os máximos regressivos, o volume de sedimentos foi suficiente para formar dunas barcanas e barcanóides que provavelmente bloquearam (junto com o crescimento das flechas de areia, como verificado através das imagens de satélite) o fluxo estuarino do canal do Guriú. Evidências associadas à ocorrência de depósitos eólico inseridos no do ecossistema manguezal (morfologias alongadas na mesma direção das atuais marcas espaço-direcionais distribuídas na planície).

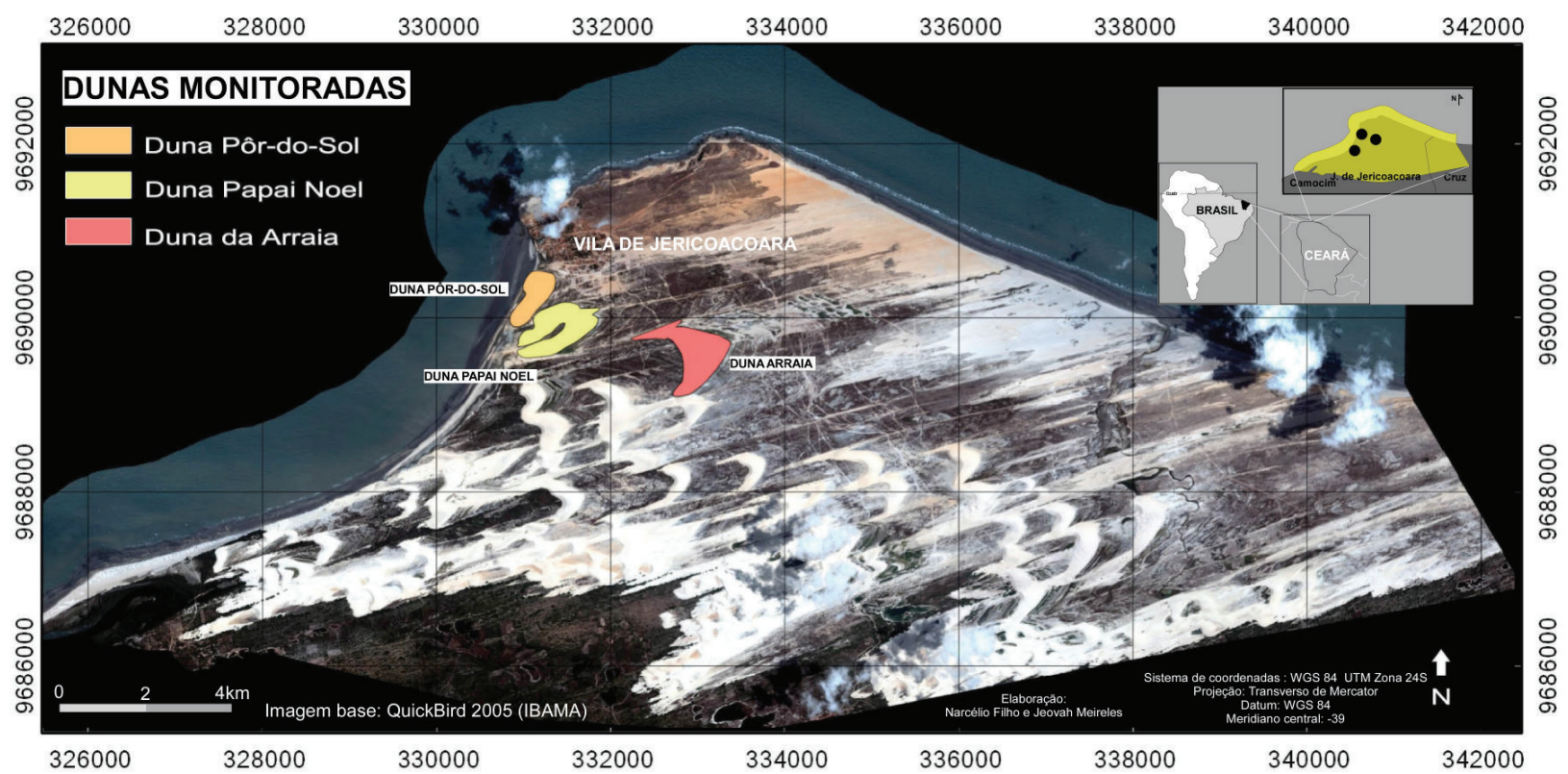

Figura 2 - Localização das dunas - Pôr-do-sol, Papai-Noel e Arraia - utilizadas para a sistematização dos intervalos de velocidade de deslocamento e evolução espaçotemporal.

Em relação a formação das dunas atuais (sobre a zona de berma), ação dos ventos na remobilização dos sedimentos é mínima, quando comparada com as dunas de $1^{\mathrm{a}}$ e $2^{\mathrm{a}}$ gerações - os sedimentos remobilizados atualmente para a formação das dunas de $3^{\text {a }}$ geração não são superiores a $10 \%$ do 
volume de sedimentos que foi utilizado para formação das dunas no interior da planície costeira vinculas a eventos de oscilações do nível relativo do mar (MEIRELES et al., 2002). As condições atuais não favorecem a formação dos campos de dunas barcanas que migram de continente adentro. Possivelmente, condições climáticas e do nível do mar diferentes das atuais foram as que proporcionaram volume de areia satisfatório para a formação de dunas móveis e fixas que ultrapassam os $60 \mathrm{~m}$ de altitude e mais de $1.000 \mathrm{~m}$ de largura e comprimento. Desta forma, pequenas oscilações no nível relativo do mar (possivelmente vinculadas à dinâmica imposta pelas oscilações da temperatura da superfície do mar com eventos El Niño/La Niña), dentro de uma curva regressiva; e associações com a plataforma continental interna (relativamente plana e rasa, rica em sedimentos arenosos e quartzosos), descobriram vastas áreas de estirâncio. Originando, assim, uma fonte de sedimentos e ventos competentes para transportar o volume de areia utilizado para a construção das dunas móveis barcanas e as mais interiores à planície. Também deveriam estar associadas às condições climáticas com índices mais elevados de aridez, para possibilitar fluxos eólicos competentes, relacionados a valores mais elevados de insolação e índices ainda mais baixos de precipitação pluviométrica.

Neste trabalho foi priorizada a dinâmica de migração de 3 (três) dunas móveis de $2^{\mathrm{a}}$ geração definidas localmente por duna do Pôr-do-sol (DPS), Papai Noel (DPN) e Arraia (DA) (Figura 3). Foram escolhidas de acordo com suas relações com os demais componentes morfológicos da planície costeira (principalmente a faixa de praia e o serrote de Jericoacoara) que interferiram na origem e evolução morfológica. Para evidenciar os objetivos foi necessário realizar mapeamento temático e sistematizar intervalo de migração das dunas para os últimos 35 anos.

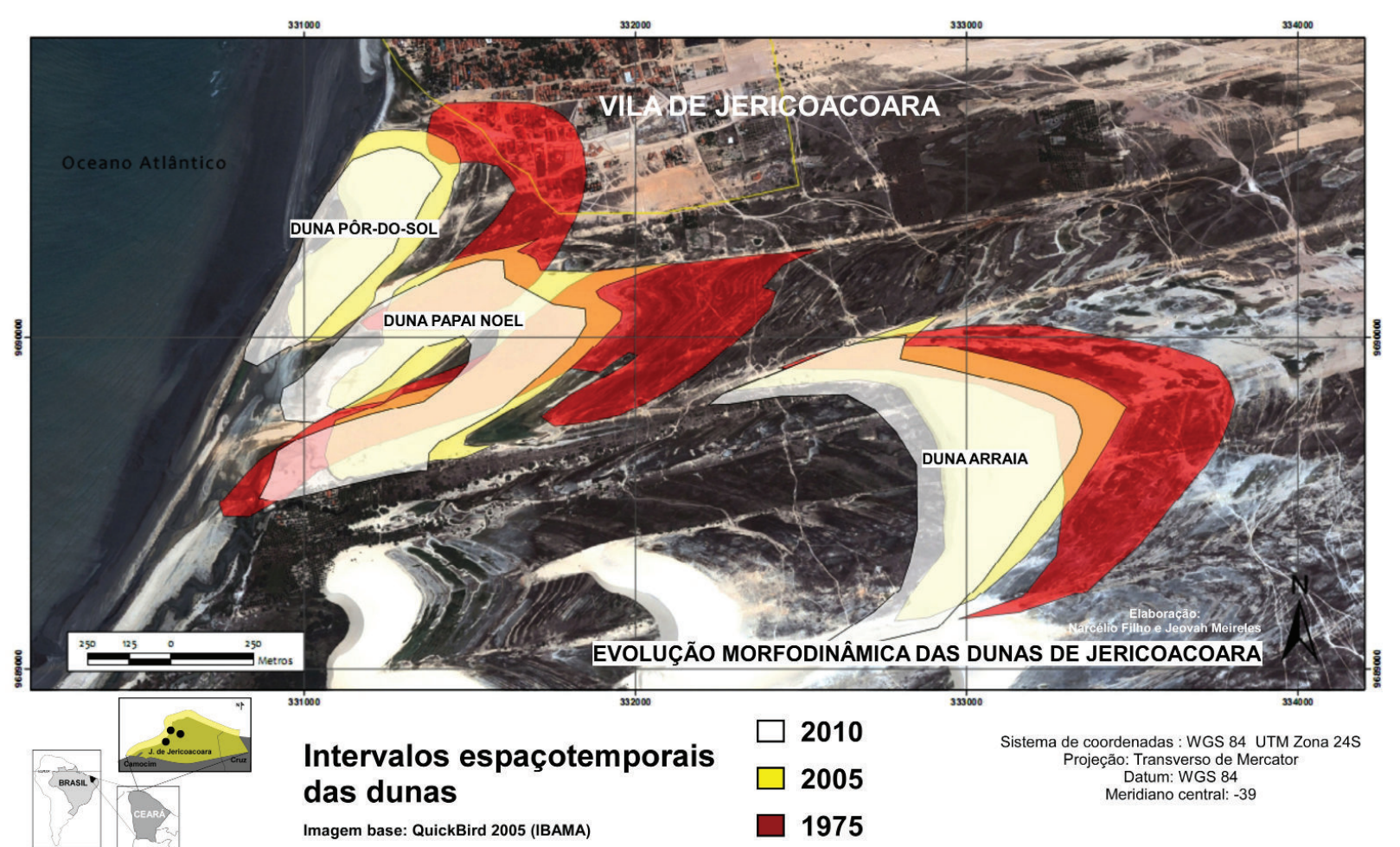

Figura 3 - Dunas barcanas e barcanóides de morfologias complexas devido dinâmica de transporte associada à incorporação de outras dunas durante a migração das maiores . Evidenciar relações com os demais sistemas ambientais diante da faixa de deslocamento. Verificar que a DPS chegou à faixa de praia.

\section{METODOLOGIA}

Foi através das imagens de satélite que iniciou-se a sistematização de um banco de dados com a utilização de ferramentas de geoprocessamento e cartografia digital. A migração das dunas foi definida através de recobrimentos aerofotogramétricos e imagens de satélite multitemporais, 
e estações georreferenciadas com GPS geodésico (dados quantitativos sobre a dinâmica morfológica). As imagens Landsat foram adquiridas gratuitamente do acervo de imagens de satélite do DGI/INPE (http://www.dgi.inpe.br/siteDgi/index_pt.php), disponibilizadas via internet no formato TIF. Foram referentes às cenas 234/062 dos satélites Landsat 1-MSS de 1975; Landsat 2-MSS (1979,1980 e 1981); 218/62 dos satélites Landsat 5-TM (1985, 1987, 1991, 1992, 1993, 1994,1999, 2000, 2001, 2002, 2006, 2007, 2008 e 2010) e Landsat 7-ETM+ além de uma imagem Quickbird de 2005. (Tabela 1). Para auxiliar na definição dos componentes morfológicos da planície foi utilizada imagem de radar SRTM obtida em 2005 e disponibilizadas pela National Aeronautics and Space Administration (NASA).

Tabela 1 - Imagens de satélite utilizadas para a extração de dados espaciais e definição do deslocamento dos campos de dunas ao longo da planície costeira de Jericoacoara.

\begin{tabular}{|c|c|c|c|c|c|}
\hline DATA & SATÉLITE & SENSOR & BANDAS & RESOLUÇÃO & COMPOSIÇÕES \\
\hline $26 / 05 / 1975$ & Landsat 1 & MSS & 4 a 7 & $80 \mathrm{~m}$ & $5 \mathrm{R}, 4 \mathrm{G}, 6 \mathrm{~B}$ \\
\hline 07/07/1979 & Landsat 2 & MSS & 4 a 7 & $80 \mathrm{~m}$ & $5 \mathrm{R}, 4 \mathrm{G}, 6 \mathrm{~B}$ \\
\hline 06/08/1980 & Landsat 2 & MSS & 4 a 7 & $80 \mathrm{~m}$ & $5 \mathrm{R}, 4 \mathrm{G}, 6 \mathrm{~B}$ \\
\hline 07/14/1981 & Landsat 2 & MSS & 4 a 7 & $80 \mathrm{~m}$ & $5 \mathrm{R}, 4 \mathrm{G}, 6 \mathrm{~B}$ \\
\hline 27/07/1985 & Landsat 5 & $\mathrm{TM}$ & 1 a 7 & $30 \mathrm{~m}$ & $5 \mathrm{R}, 4 \mathrm{G}, 3 \mathrm{~B}$ \\
\hline $17 / 07 / 1987$ & Landsat 5 & $\mathrm{TM}$ & 1 a 7 & $30 \mathrm{~m}$ & $5 \mathrm{R}, 4 \mathrm{G}, 3 \mathrm{~B}$ \\
\hline $10 / 06 / 1991$ & Landsat 5 & $\mathrm{TM}$ & 1 a 7 & $30 \mathrm{~m}$ & $5 \mathrm{R}, 4 \mathrm{G}, 3 \mathrm{~B}$ \\
\hline $31 / 08 / 1992$ & Landsat 5 & $\mathrm{TM}$ & 1 a 7 & $30 \mathrm{~m}$ & $5 \mathrm{R}, 4 \mathrm{G}, 3 \mathrm{~B}$ \\
\hline $10 / 06 / 1993$ & Landsat 5 & $\mathrm{TM}$ & 1 a 7 & $30 \mathrm{~m}$ & $5 \mathrm{R}, 4 \mathrm{G}, 3 \mathrm{~B}$ \\
\hline $10 / 06 / 1994$ & Landsat 5 & $\mathrm{TM}$ & 1 a 7 & $30 \mathrm{~m}$ & $5 \mathrm{R}, 4 \mathrm{G}, 3 \mathrm{~B}$ \\
\hline 10/06/1999 & Landsat 5 & $\mathrm{TM}$ & 1 a 7 & $30 \mathrm{~m}$ & $5 \mathrm{R}, 4 \mathrm{G}, 3 \mathrm{~B}$ \\
\hline Geocover 2000 & Landsat 5 & ETM+ & 1 a 7 PAN & $15 \mathrm{~m}$ & 2R, 4G, 7B + Pancromática \\
\hline 19/08/2000 & Landsat 5 & ETM+ & 1 a 7 PAN & $15 \mathrm{~m}$ & 5R, 4G, 3B + Pancromática \\
\hline $01 / 09 / 2001$ & Landsat 5 & ETM+ & 1 a 7 PAN & $15 \mathrm{~m}$ & 5R, 4G, 3B + Pancromática \\
\hline $19 / 08 / 2002$ & Landsat 5 & $\mathrm{TM}$ & 1 a 7 & $30 \mathrm{~m}$ & $5 \mathrm{R}, 4 \mathrm{G}, 3 \mathrm{~B}$ \\
\hline 2005 & QuickBird & QuickBird & - & $0,70 \mathrm{~cm}$ & - \\
\hline $22 / 06 / 2006$ & Landsat 5 & $\mathrm{TM}$ & 1 a 7 & $30 \mathrm{~m}$ & $5 \mathrm{R}, 4 \mathrm{G}, 3 \mathrm{~B}$ \\
\hline 25/08/2007 & Landsat 5 & $\mathrm{TM}$ & 1 a 7 & $30 \mathrm{~m}$ & $5 \mathrm{R}, 4 \mathrm{G}, 3 \mathrm{~B}$ \\
\hline $12 / 09 / 2008$ & Landsat 5 & $\mathrm{TM}$ & 1 a 7 & $30 \mathrm{~m}$ & $5 \mathrm{R}, 4 \mathrm{G}, 3 \mathrm{~B}$ \\
\hline $30 / 09 / 2010$ & Landsat 5 & $\mathrm{TM}$ & 1 a 7 & $30 \mathrm{~m}$ & $5 \mathrm{R}, 4 \mathrm{G}, 3 \mathrm{~B}$ \\
\hline
\end{tabular}

Fonte: Banco de dados da pesquisa/CNPq.

Os dados de imagens brutos sofreram transformações através de técnicas de processamento digital de imagens (PDI), produzindo os primeiros elementos da base de dados, para produção de informações geoambientais. O PDI - pré-processarnento, processamento de cores, realçamento de contraste, filtragem espacial, manipulações espectrais e classificação - permitiu tratar os dados brutos para facilitar a identificação e a extração das informações contidas nas imagens. 
O software utilizado para o georreferenciamento e tratamento das imagens foi ENVI 4.7, adotando o sistema de projeção cartográfica UTM (Universal Transverso de Mercator) com o Datum WGS-84. Todas as imagens foram georreferenciadas com base no mosaico de imagens do satélite Landsat ETM+ do ano de 2000 (resolução espacial 14,25m e bandas 2, 4 e 7), disponibilizada pelo programa Geocover da NASA. Posteriormente, as imagens foram submetidas a uma análise comparativa de overlay, com cada cena sobreposta a correspondente Geocover 2000. Procedimentos que definiram a qualidade da precisão do georreferenciamento realizado anteriormente. Para as imagens de alta resolução Quickbird, utilizadas para extração das informações geográficas de precisão, utilizou-se receptores geodésicos do sistema Navstar GPS, com precisão nominal de $5 \mathrm{~mm}$ +1 ppm. Os dados foram processados em softwares do fabricante.

As imagens foram sobrepostas para a definição do deslocamento das dunas e, com a utilização do recurso de transparência, foi possível comparar alterações morfológicas durante o processo de migração. Estes dados foram digitalizados em forma de vetor shapefile e submetidos a técnicas de geoprocessamento e cálculos de áreas e perímetros das dunas móveis. Nessa etapa utilizou-se um total de 20 imagens de satélite de alta e média resolução espacial, que evidenciam 35 anos de evolução morfodinâmica do conjunto dunar (Figura 04).

$\mathrm{O}$ apoio terrestre para suporte às determinações das coordenadas planialtimétricas utilizadas para georreferenciamento e geração de curvas de nível, foi determinado através da estação de referência da Rede GPS Estadual, localizada na cidade de Sobral/CE. Para o rastreamento de pontos foi adotado o método cinemático, com taxa de gravação de 5 segundos. Para a inicialização será utilizado o método da "barra", recomendado pelo fabricante, com receptores de uma frequência.

Para definir os elevados níveis de complexidade do sistema costeiro em análise, foram agrupadas as interrelações mais amplas que interferem na evolução do campo de dunas (Figura 5). Foram definidos de acordo com os resultados de pesquisas evidenciados por Meireles e Rúbio (2000) ao tentarem definir as interações e interdependências dos componentes morfológicos do litoral cearense vinculados às alterações climáticas e mudanças no nível relativo do mar. Evidenciou-se, desde a perspectiva temporal, que o sistema costeiro - diante dos complexos fluxos de matéria e energia tem como objetivo (finalidade) desde o ponto de vista físico, lograr a mais absoluta permanência, para o qual regula seu gasto de energia (mínimo gasto), fato que, dado o atual nível de conhecimento somente estudamos através dos funcionamentos prováveis da dinâmica das interrelações e geoelementos. Deste modo, se estabelece no âmbito temporal o valor ótimo, o que necessariamente se traduz, em muitos casos, na involucionista idéia de equilíbrio (estabilidade, clímax), que é quando aparece a identidade própria ou expressão máxima do sistema ou fase potencial máxima. Porém, a lógica de evolução do meio assinala que depois da fase de máxima estabilidade se inicia a decadência irreversível do sistema (entropia) ao menos desde o ponto de vista físico. Quer dizer, se inicia um intercâmbio de matéria e energia sempre de maneira crescente a favor do sistema novo. Desta forma, a planície costeira, sistema ambiental de evidente convergência dos principais fluxos de matéria e energia (incluindo os derivados das diversas formas de uso e ocupação), atua como zona de recarga de sedimentos, suporte para os ecossistemas e recursos ambientais para uma elevada diversidade de interesses econômicos e sociais.

\section{CARACTERÍSTICAS CLIMÁTICAS}

A planície costeira de Jericoacoara é representada por um conjunto de unidades morfológicas diretamente relacionadas com os componentes meteorológicos locais e regionais. A ação dos ventos, a sazonalidade das precipitações pluviométricas e a insolação, atuam na dinâmica de transporte de sedimentos, formação de lagoas costeiras e comportamento ecodinâmico da fauna e flora do Parque. 

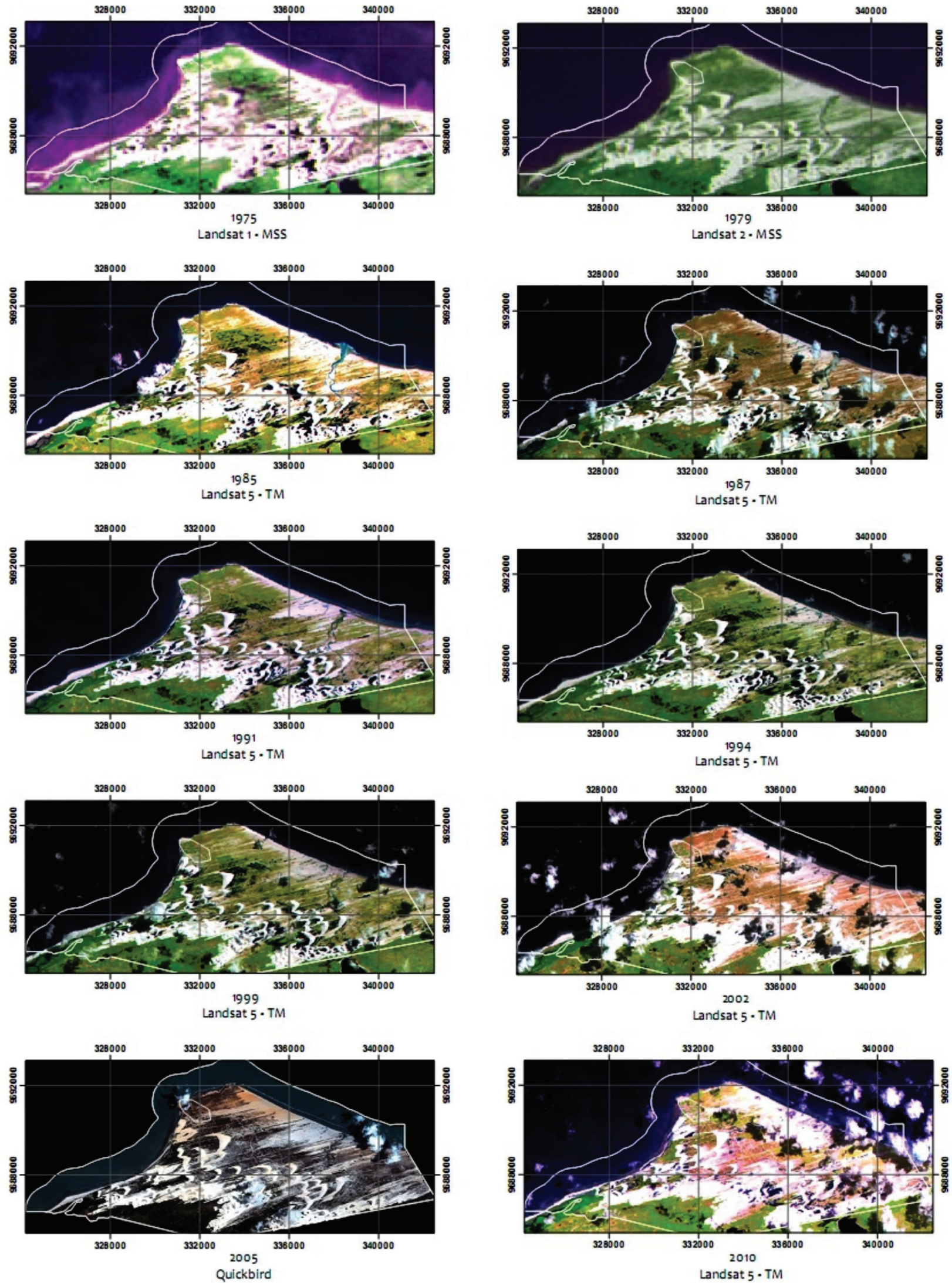

Figura 4 - Parte das imagens de satélite utilizadas para a definição da evolução morfológica e espaçotemporal (1975 a 2010) dos campos de dunas do Parna Jericoacoara. 
Os ventos na região Nordeste do Brasil são regidos pela presença de um forte ciclo temporal definido por um período anual. As mudanças ocorridas neste sistema climático estão agregadas às variações da ZCIT (Zona de Convergência Intertropical), uma vez que controla esses ventos. A ZCIT é uma zona ou região marcada pela confluência dos ventos alísios de nordeste e sudeste, por conseguinte corresponde a uma intensa nebulosidade e baixa pressão atmosférica.

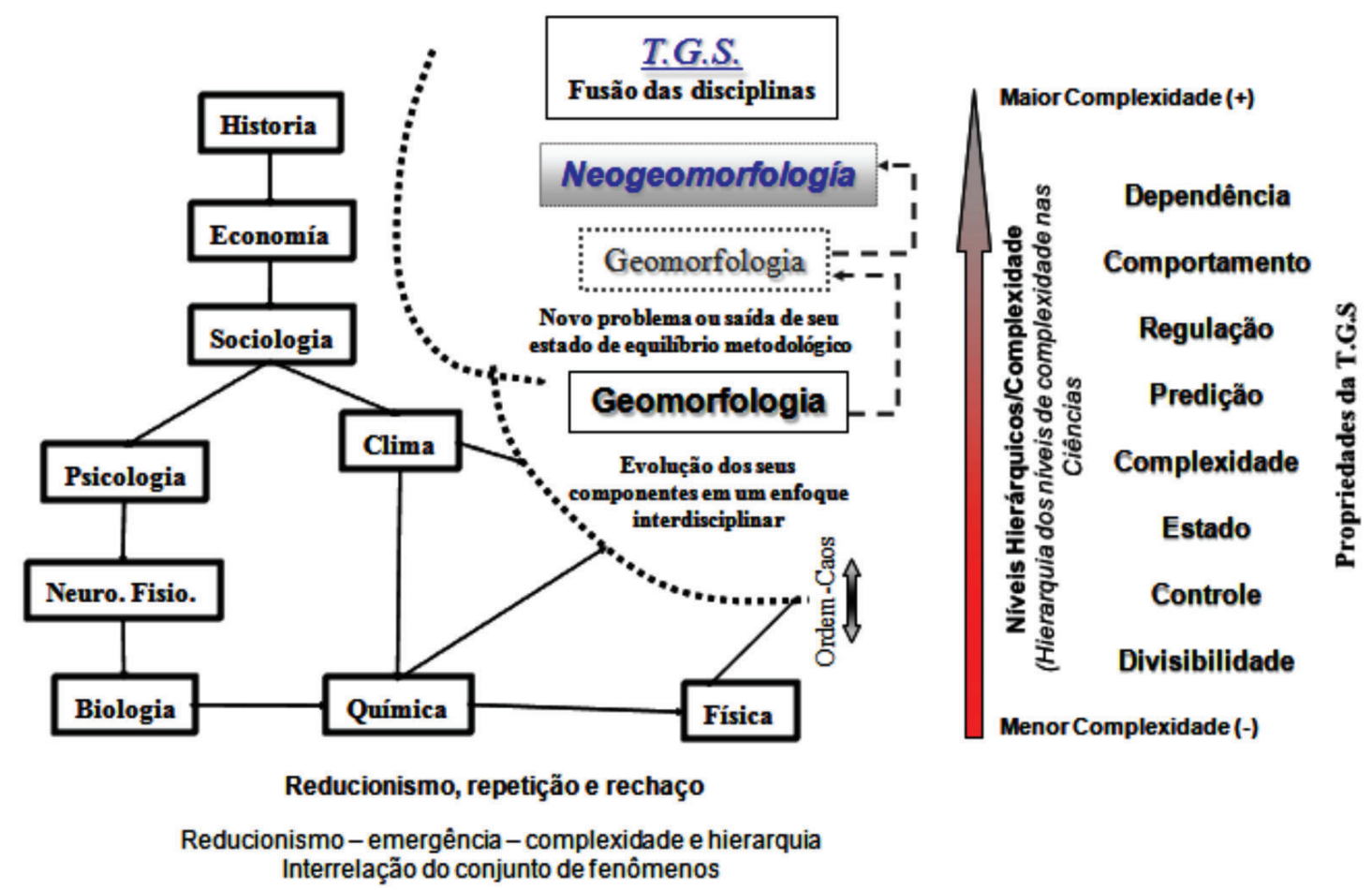

Figura 5 - Modelo de integração dos níveis de complexidade em uma abordagem sistêmica (Meireles e Rúbio, 2000).

Esta zona de convergência migra de sua posição mais ao norte, no oceano Atlântico, em direção ao sul, durante o verão austral. Geralmente, os ventos alísios de sudeste são mais intensos quando a ZCIT está ao norte nos meses de agosto a outubro, diminuindo progressivamente com sua migração para o equador, até alcançar os mínimos valores anuais durante os meses de março e abril, quando os ventos de sudeste são mais fracos (QUADRO et al. 1997; MARENGO e UVO, 1997 e Maia et al., 1996).

A variação anual da precipitação pluviométrica é controlada pelo movimento da ZCIT, principal sistema sinótico responsável pela quadra chuvosa no Estado, que dependendo da sua posição e tempo, pode provocar chuvas intensas. Com um regime pluviométrico variável, todavia, as precipitações ocorrem no primeiro semestre, distribuindo-se entre os meses de março e maio (BRANDÃO, 1995). Para a região em estudo, a precipitação média anual alcança valores em torno de 823,8 mm (IPECE, 2010).

O regime pluviométrico da área de estudo é do tipo tropical com a estação chuvosa concentrada em cinco meses consecutivos. A estação chuvosa começa geralmente no mês de fevereiro, com os valores máximos frequentemente associados aos meses de março e abril. A parir de julho as precipitações diminuem até o mês de novembro. O primeiro semestre do ano responde, em média, por mais de $90 \%$ das precipitações anuais. A Figura 6 mostra imagens de satélite (FUNCEME, 2006) evidenciando a diferença de cobertura de nuvens durante os períodos anuais de maior precipitação e o de estiagem.

O vento apresenta-se no litoral como um importante componente da dinâmica da paisagem natural e subsistente para a composição da morfologia local, principalmente na migração dos 
campos de dunas e aporte de areia para a planície de aspersão eólica. As direções predominantes dos ventos nesta planície litorânea são de SE, ESE, E e NE. As médias de velocidade chegam a superar os $4 \mathrm{~m} / \mathrm{s}$ nos meses de estiagem (segundo semestre anual). No inicio da estação chuvosa, com a chegada da ZCIT, registram-se mudanças na direção dos ventos, passando a predominar os de nordeste. No período de estiagem (segundo semestre) procede-se um predomínio dos ventos de $\mathrm{SE}$, cujas velocidades são as mais intensas.
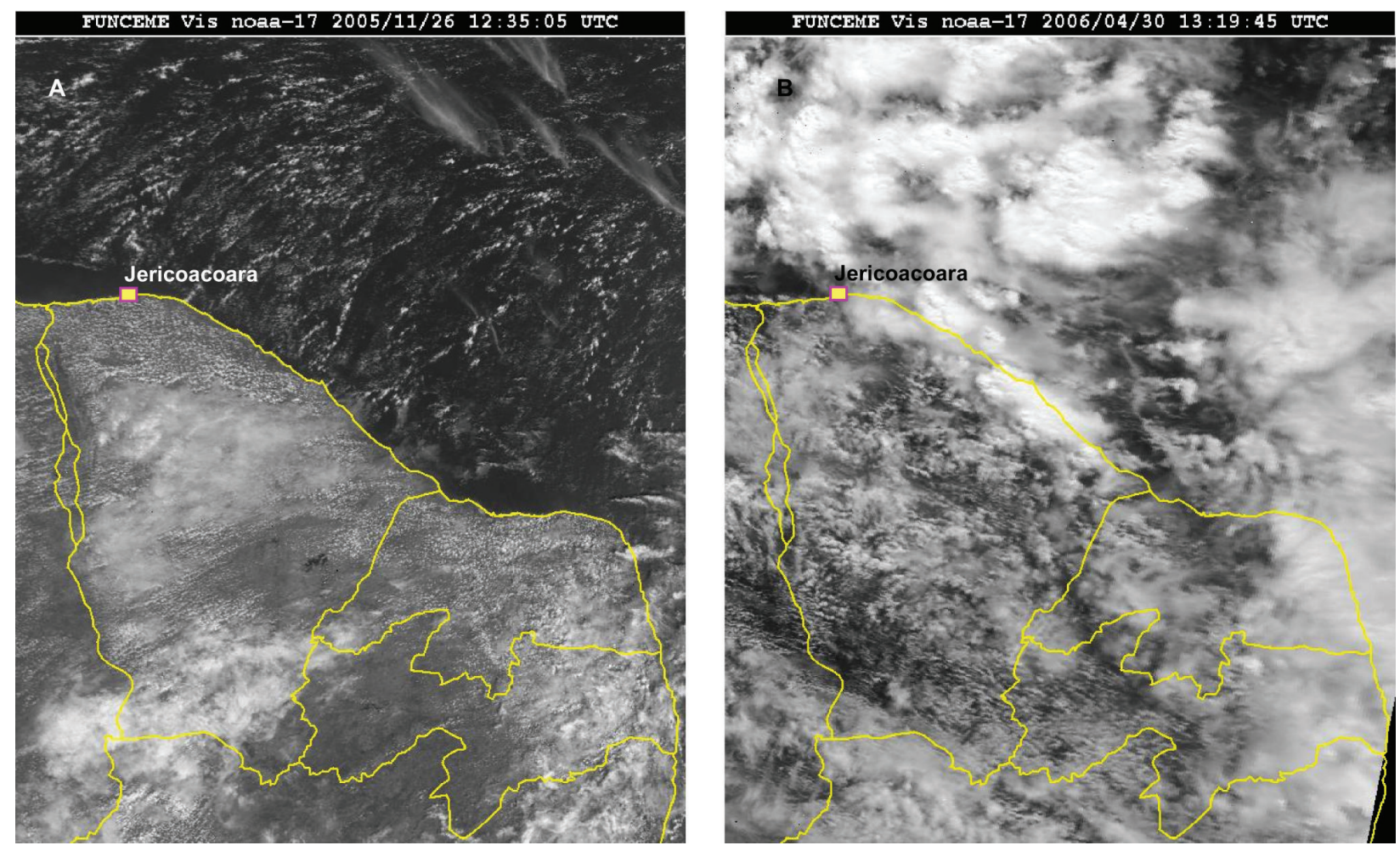

Figura 6 - imagens provenientes dos satélites meteorológicos de órbita polar da série NOAA (National Oceanic and Atmospheric Administration) (FUNCEME, 2011) evidenciando a diferença de cobertura de nuvens durante os períodos anuais de estiagem (A) e de maiores índices pluviométricos (B). Verificar a eleva nebulosidade concentrada no oceano Atlântico e sobre a zona costeira cearense (associada ao período chuvoso).

A integração entre as médias de pluviometria, velocidade dos ventos e insolação é um importante indicador para a análise da dinâmica morfogenética da planície costeira onde está inserida a unidade de proteção integral. No primeiro semestre, os valores tanto da intensidade dos ventos quanto da insolação são menos elevados, apresentando índices altos de precipitação. No segundo semestre, ocorre uma diminuição dos índices pluviométricos e eleva-se a velocidade dos ventos e a insolação. Desta forma, a migração das dunas é mais efetiva no segundo semestre (menores índices pluviométricos, ventos mais elevados e maior insolação), juntamente com uma diminuição do nível hidrostático do lençol freático e assim a incidência das lagoas sobre a planície costeira. É importante evidenciar que o regime dos ventos atua de modo a definir o formato e a orientação das dunas (KOCUREK e EWING, 2005) mas, localmente, na planície costeira de Jericoacoara, as dunas foram associadas com a fisiografia da linha de costa e a plataforma continental, e que possivelmente atuaram na disponibilidade dos sedimentos, distribuição e compêtencia dos ventos para a deriva eólica.

\section{ASPECTOS REGIONAIS E LOCAIS RELACIONADOS À EVOLUÇÃO DAS DUNAS}

Os eventos glaciais e interglaciais que ocorreram durante o Quaternário, com oscilações do nível do mar na ordem de dezenas e até uma centena de metros, ocasionaram importantes mudanças 
nos processos geoambientais globais, os quais também provocaram reflexos no litoral brasileiro. Comparando registros de isótopos de oxigênio em sondagens realizadas em diferentes regiões do planeta (incluindo registros nos trópicos, hemisfério Norte e Antártica) SHACKLETON (1987); BROECKER e DENTON (1990); LEDRU, et al. (1996), THOMPSON et al. (1995), entre outros, demonstraram a extensão planetária dos últimos eventos glaciais.

Em áreas mais específicas do litoral cearense foram definidos indicadores geológicos e geomorfológicos de variações do nível do mar relacionados com níveis de erosão escalonados em plataformas de abrasão marinha, paleopavimentos de mangue, terraços marinhos holocênicos e pleistocênicos, antigos corais e gerações de dunas. A integração geoambiental Foi possível definir 5 eventos eustáticos que fundamentaram a origem de um complexo conjunto de indicadores geoambientais que denunciaram os eventos de mudanças do nível relativo do mar e climáticas na construção da planície costeira cearense (MEIRELES et al., 2002).

A presença de paleoplataformas de abrasão escalonadas, com notchs (entalhes basais), ao longo da planície costeira de Jericoacoara atribuídos a distintos níveis altimétricos do mar (MEIRELES et al. 2003), diferentes da cota atual, foi relacionada com as oscilações de alta frequência. Estas estruturas de erosão foram estudadas por SUNAMURA (1994) e PIRAZOLLI (1996) e foram utilizadas para a definição de cotas altimétricas do nível do mar diferentes das atuais. Oscilações dessa natureza foram evidenciadas na costa Este brasileira, quando há 4.800 e 2.700 anos A.P. se produziram oscilações da ordem de 3m no nível relativo do mar (MARTIN, et al., 1982).

As dunas móveis presentes no litoral de Jericoacoara exercem importante função como reservatórios de sedimentos para a manutenção de um aporte regulador de areia ao longo da faixa de praia. Atuam de modo a evitar eventos erosivos, ao contribuir com sedimentos para a deriva litorânea (ação das ondas e marés). São ambientes fortemente instáveis uma vez que são controlados pela incidência dos ventos de direção preferencial leste e nordeste, os quais orientam o caminho das dunas móveis do setor leste da linha de costa para o interior do Parque.

Quanto ao uso potencialmente turístico das dunas, foram definidas limitações, principalmente as relacionadas com a desconfiguração morfológica do corpo dunar, impermeabilização e alterações na quantidade de água armazenada, construção de vias de acesso, fixação com a implantação de equipamentos urbanos e a mineração. No caso das dunas do Parque, o principal risco de uso inadequado pelo turismo e associado aos aspectos geodinâmicos e ecológicos, é o transito de veículos de tração sobre o corpo dunar. Verificou-se que altera o transporte das areias através da indução de processos turbulentos na remobilização dos sedimentos e acarreta mudanças no seu aspecto morfológico natural.

A plataforma continental plana e muito extensa possibilitou, em oscilações do nível do mar de pequenas amplitudes, a exposição de extensas áreas com sedimentos representativos de fácies quartzosa e biodetrítica para o transporte eólico. No litoral oeste cearense, eventos desta natureza, que originaram extensos depósitos de sedimentos eólicos, foram representados pela ocorrência de eolianitos em trechos contínuos de até $28 \mathrm{~km}$ (MEIRELES et al., 2002). Associados ao eolianitos, foram registradas ocorrências de depósitos de mangue (com restos vegetais) em áreas atualmente submersas durante a maré baixa e afastados do limite da linha de costa em até 1,2km (plataforma associadas à zona costeira dos municípios de Icapuí e Camocim).

As interferências humanas foi relacionada com o trânsito de veículos incrementado pelo fluxo de turistas (MEIRELES et al., 2011). Os impactos ambientais relacionados com a interferência de veículos sobre campos de dunas e faixa de praia foram amplamente tratados na literatura científica nacional e internacional (STEPHENSON, 1999; PRISKIN,2003; STEINBACK, 2004; MEIRELES, 2005). Enfocaram os danos à biota e ao conjunto de unidades morfológicas da planície costeira. O efeito da circulação de veículos sobre os terrenos arenosos promoveu a origem de trilhas compactadas e geradoras de processos erosivos com intensa remobilização de areia. Sobre a planície de aspersão eólica (terrenos planos com intensa movimentação de areia pela ação dos ventos) originou sulcos 
desde as trilhas associadas ao acesso dos veículos às dunas móveis e à vila de Jericoacoara (Figuras 7 e 8). Durante os meses com ventos mais intensos (agosto a dezembro) estes sulcos evoluíram para canais de fluxo turbulento orientado na direção preferencial dos ventos.
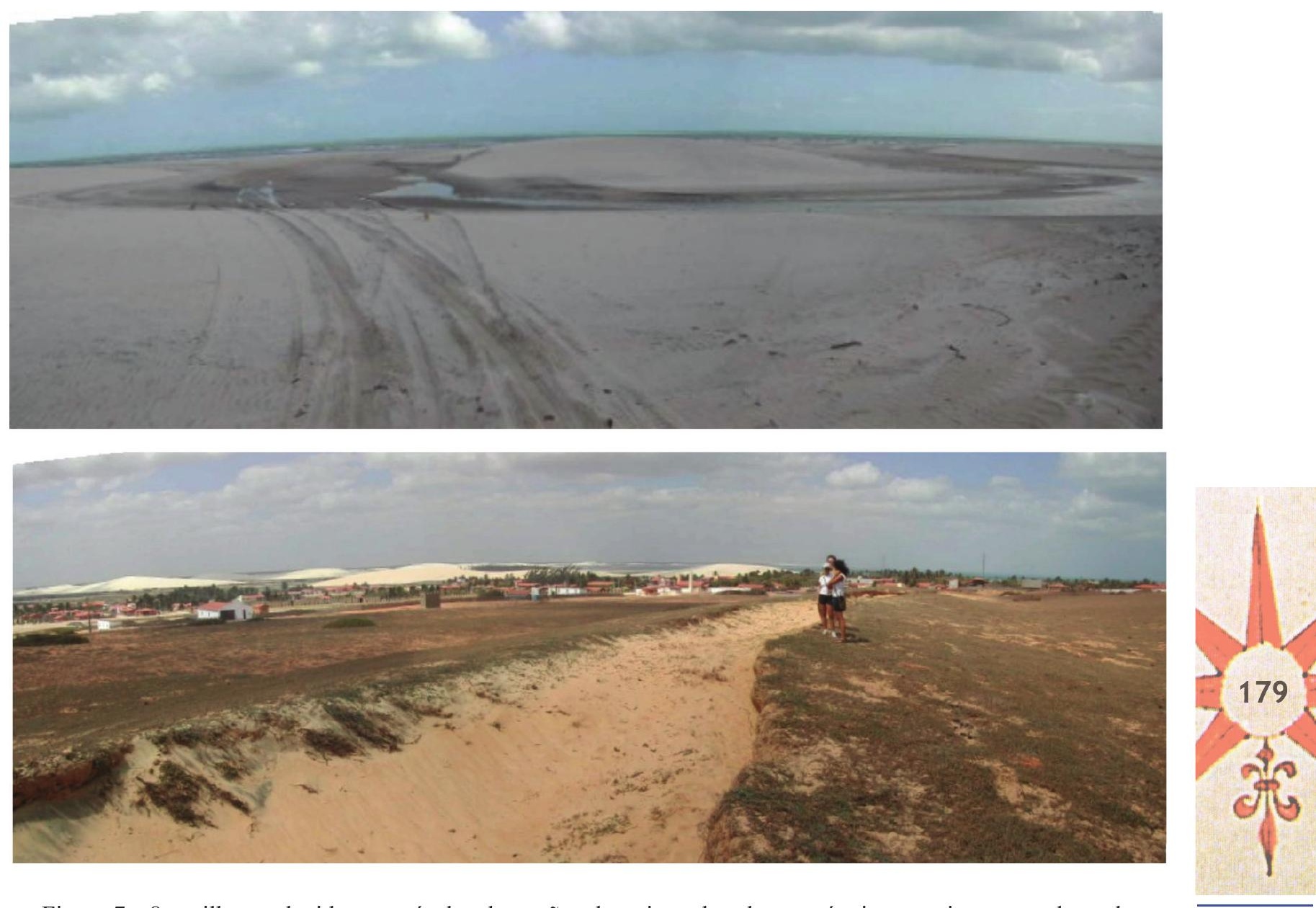

Figura 7 e 8 - trilha produzida por veículos de tração e buguies sobre dunas móveis e canais provocados pelo trânsito de veículos. Orientaram o transporte de areia na direção da vila de Jericoacoara.

Quando os veículos se aproximam das dunas móveis promovem a compactação dos terrenos areno-argilosos (associados às lagoas interdunares no sopé das dunas) e, ao iniciarem a subida pelo dorso da duna (setor à barlavento) e quando descem pela face de avalanche (à sotavento), promovem impactos relacionados com:

i. alterações na dinâmica (velocidade e direção de fluxo) de transporte das areias;

ii. alterações nas estruturas sedimentares, originadas pelo processo natural de transporte de areia em migração da duna, através da compactação da superfície arenosa;

iii. introdução de rugosidades (sulcos promovidos pelos pneus) ao longo do dorso e face de avalanche;

iv.mudanças nas tensões de elevação, empuxe e arraste dos sedimentos, alterando a dinâmica de transporte de areia em rolamento, saltação e suspensão;

v. incremento da erosibilidade dos ventos sobre o dorso da duna e no contato com a base da estrutura dunar;

vi. indução de deslizamentos de areia na face de avalanche, incrementando o soterramento de lagoas interdunares e da vegetação associada; 
vii. indução de processos turbulentos como variável do vento na remobilização dos sedimentos; viii. origem de sulcos a partir dos rastos dos pneus logo que saem da faixa de estirâncio, entram na zona de berma e na planície de aspersão eólica;

ix. quando os veículos mantêm o rumo de acesso à duna guardando a mesma direção preferencial dos ventos, os sulcos são aprofundados (através da continuidade do trânsito de carros e ação dos ventos nos meses de estiagem) até a base da duna e, ao ascenderem pelo seu dorso, alteram a morfologia desse setor do corpo dunar;

$\mathrm{x}$. as marcas dos pneus sobre a duna induzem um transporte diferencial, incrementando a mobilidade da areia e alterando o volume naturalmente acumulado pela ação dos ventos;

xi. o movimento de veículos sobre as dunas localizadas nas proximidades da área urbanizada (predominantemente no acesso leste), altera a forma dunar, certamente incrementando o deslocamento de areia na direção das dunas mais à oeste e para as proximidades da vila. Neste setor foram observadas composições dunares vinculadas diretamente ao transporte de areia gerada pela circulação de veículos.

A intensa mobilização dos sedimentos produzida pelos danos originados pelos veículos, também se direcionou para outros ecossistemas (lagoas, terraços e tabuleiro), degradando a morfologia, fauna e flora. Verificou-se que, ao iniciarem o processo de subida, os veículos promovem o esmagamento e soterramento de vegetação pioneira associada ao sopé das dunas móveis. São áreas indutoras do processo de fixação das dunas e que resguardam uma fauna diversificada. Quando os veículos alteram a estrutura interna do depósito eólico, promovem também alterações na permeabilidade, porosidade e compactação.

A figura 9 mostra o adensamento das trilhas de acessos à vila de Jericoacoara com o fluxo de veículos provenientes da lagoa Grande e da praia do Preá. Foi relacionado ao aumento de veículos que utilizam esta área do Parque de forma desordenada e seguindo rumos aleatórios, impostos pela dificuldade de acesso (presença de lagoas e variação das marés) ou em busca das dunas de segunda geração para as atividades turísticas. Durante as atividades de campo foi possível evidenciar que as areias está atingindo as ruas, soterrando os acessos e acumulando-se nas edificações e aproximando-se da DPS.

Durante a estiagem, a gramínea existente nas áreas não impactadas pelos veículos (normalmente nos platôs originados pela sequência de canais promovidos pelos veículos) é em parte coberta pelos sedimentos, incrementando o volume de areia em transporte eólico. Caso continue o acesso de veículos de forma aleatória, sem obedecer ao traçado de uma trilha-eixo, ocorrerá um incremento dos canais existentes (aprofundamento pelo aumento do volume de areia em transporte pelo vento) e abertura de novas trilhas de veículos, com a indução de novos corpos dunares que poderão alcançar de forma mais generalizada o setor urbano.

\section{EVOLUÇÃO ESPAÇOTEMPORAL DAS DUNAS}

Como resultado obteve-se, inicialmente, a distribuição espacial dos diversos componentes geoambientais (Figura 10). Através da comparação da distribuição espaçotemporal das morfologias dunares, entre os anos de 1975 e 2010, evidenciaram-se mudanças significativas na área, perímetro e tendência de deslocamento das dunas. Foi possível constatar a ação dos fluxos de matéria e energia vinculados com migração continuada direcionada para a faixa de praia (setor de bypassing de sedimentos). Foi detectada uma tendência geral dos corpos dunares de diminuição da área e alterações de alta frequência do perímetro (complexas alterações no contorno das dunas), principalmente nos mais próximos do setor urbana da vila e do serrote de Jericoacoara (Figura 11). 


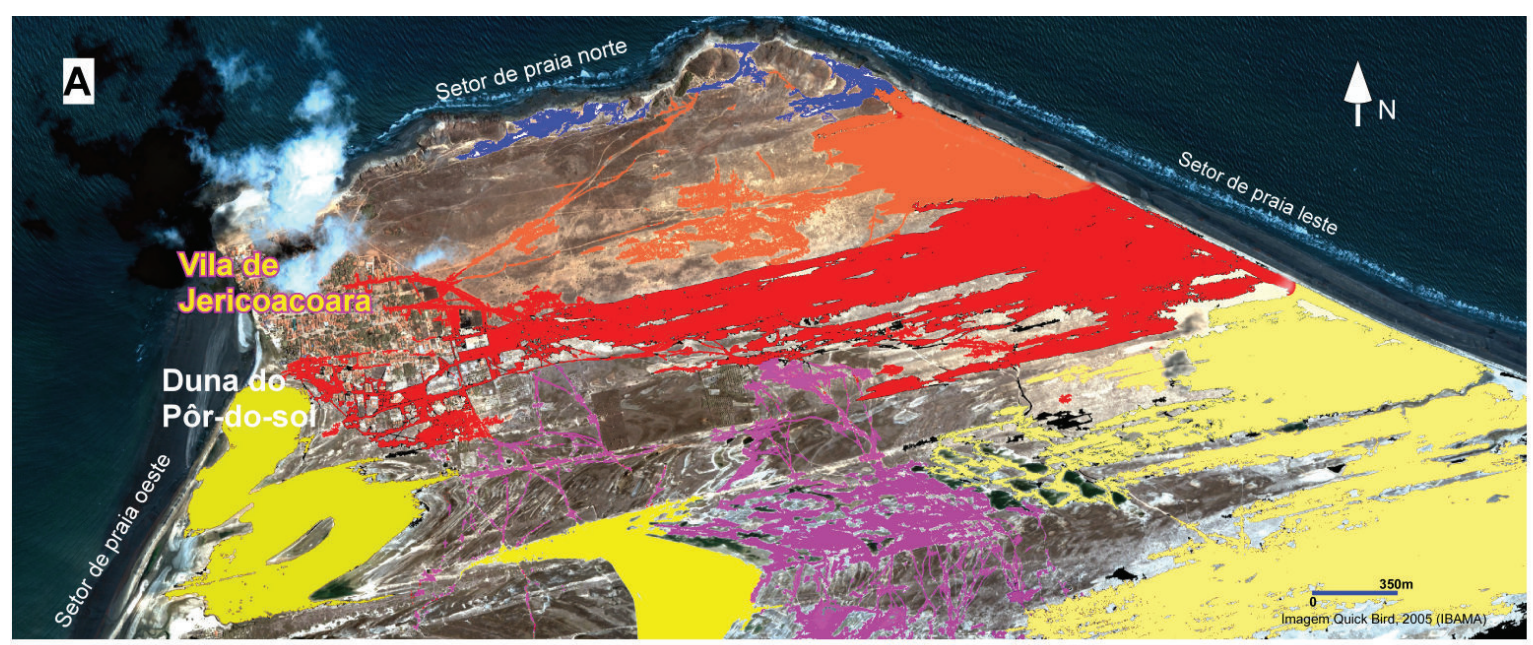

Mobilização dos sedimentos relacionada com o tráfego de veículos provenientes da trilha da Praia do Preá. Mais nas proximidades da faixa de praia o transporte originou lençois de areia e, nas proximidades da vila, o deslocamento das areia produziu uma seqüência de copor dunares.

Setor da planície de aspersão eólica e serrote da Pedra Furada em processo de atenuação do transporte de sedimentos após a proibição do acesso de veículos (ações coordenadas pela Chefia do Parque).

Setor em processo de mobilização de sedimentos desencadeado pelo intenso tráfego de veículos realizado de forma aleatória e desordenado a partir da trilha Lagoa grande.

Dinâmica imposta pela ação natural do transporte de areia pela ação dos ventos. Lençois de areia vinculados ao setor de praia leste.

Dunas barcanas de grande porte associadas ao transporte de sedimentos à retaguada induzido pelo intenso tráfego de veículos.

Cobertura sedimentar eólica em setores do serrote da Pedra Furada.

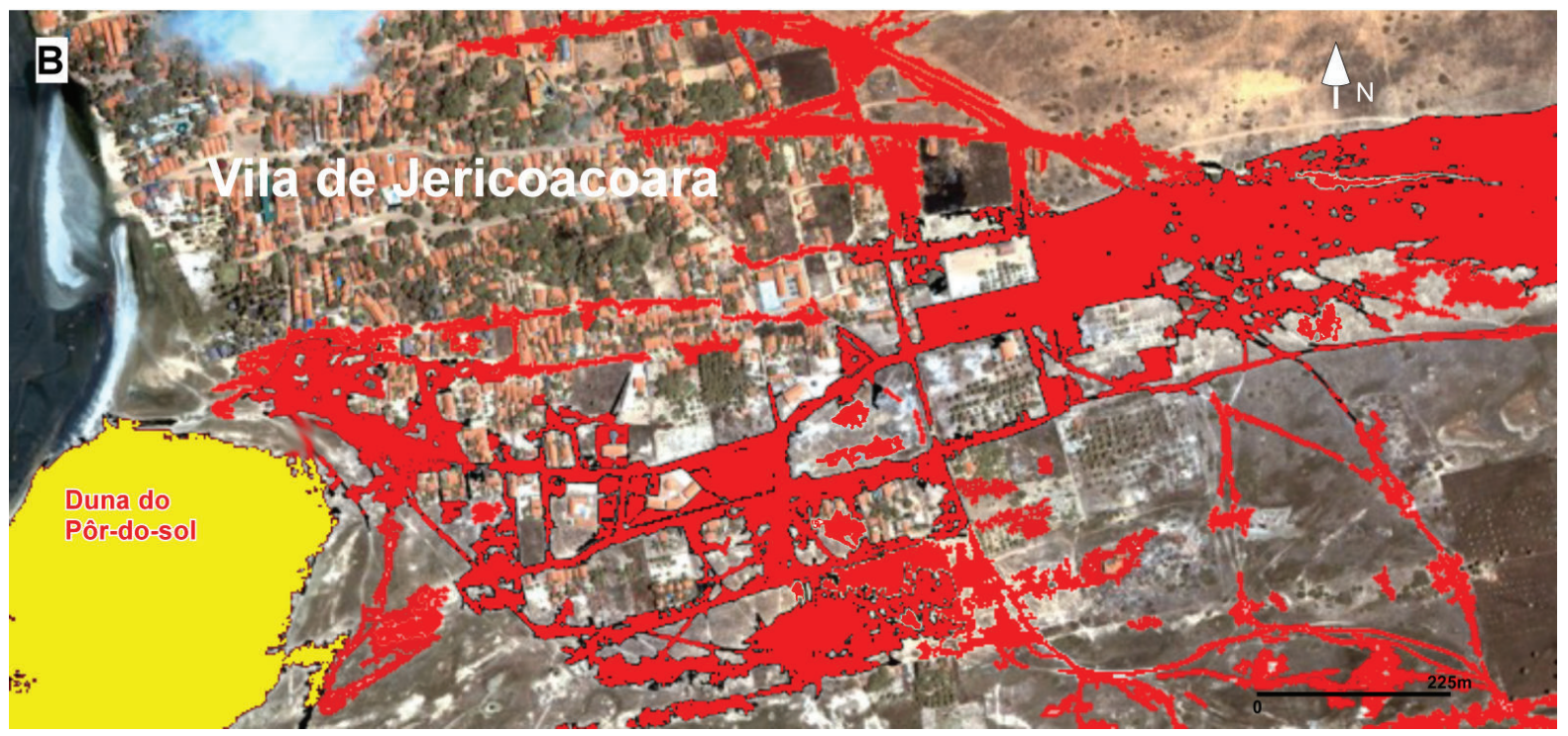

Figura 9 - Dinâmica dos sedimentos eólicos associada ao tráfego desordenado e aleatório de veículos (A) e detalhe do movimento dos sedimentos que entraram no setor urbanizado da vila de Jericoacoara (B). (Imagem de satélite QuickBird de 2005). 
MEIRELES, A. J. A.

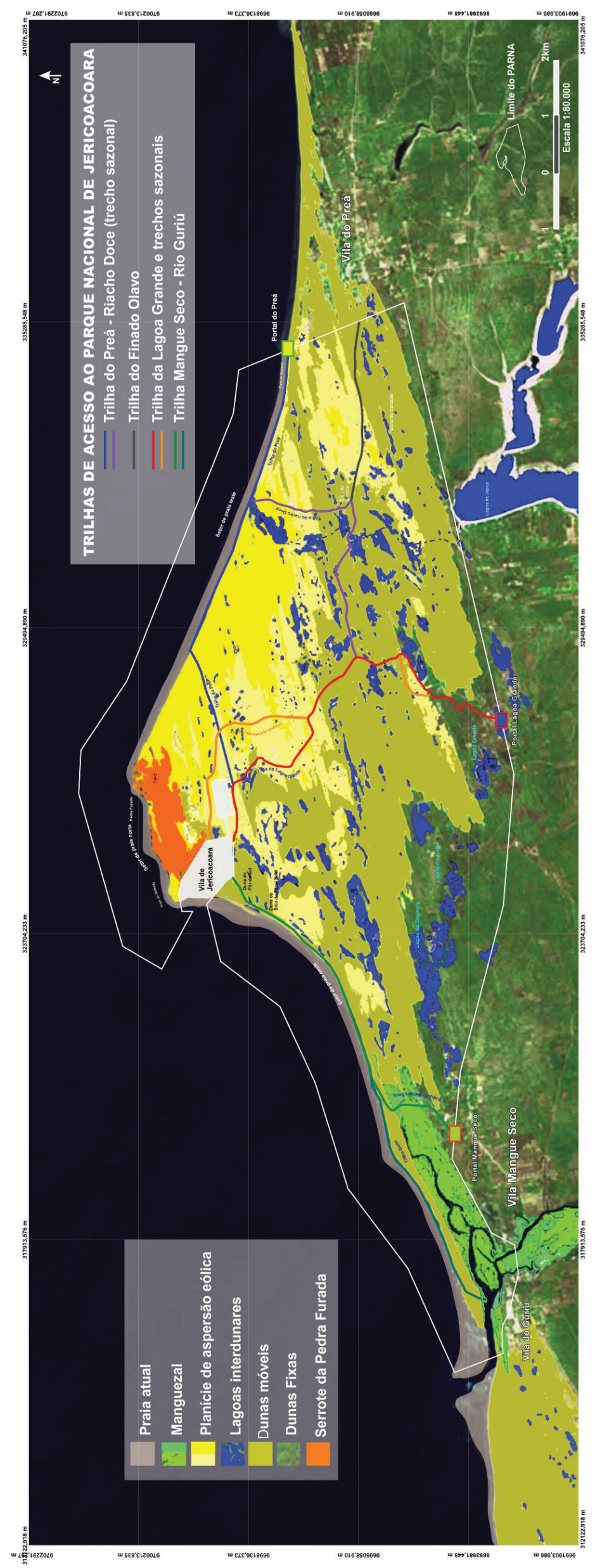

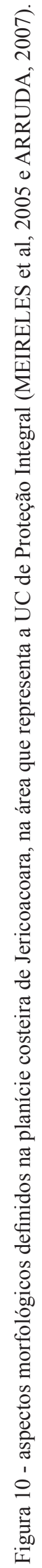



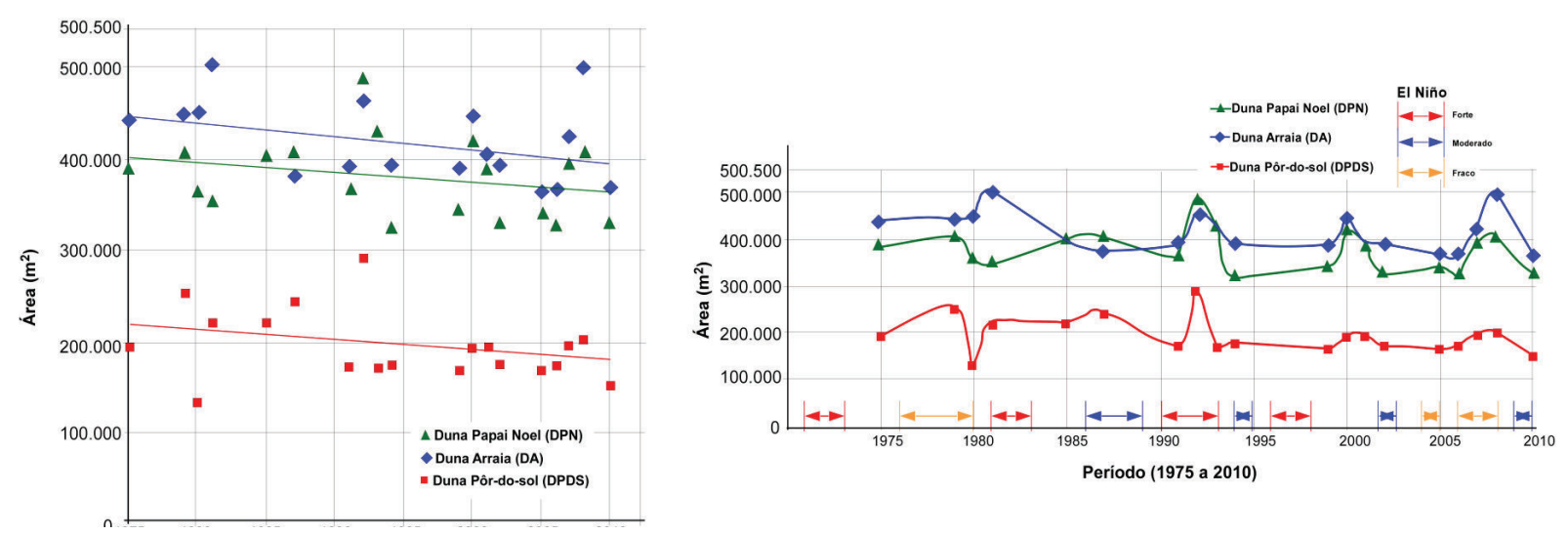

Figura 11 - Valores médios de área das dunas. Foram associados aos eventos El Niño.

A área da DPDS (média de $198.472 \mathrm{~m}^{2}$ ) para o período 2005 a 2010, registrou uma diminuição de aproximadamente $18.500 \mathrm{~m}^{2}$, definindo uma tendência de déficit constante de sedimentos durante seu deslocamento. Essa diminuição foi relacionada ao fato de estar se movimentando sobre o promontório de Jericoacoara e ter atingido o setor de bypass - alcançou a faixa de praia e os sedimentos passaram a ser transportados pela ondas - desde o início dos anos 1990. Neste período foi possível definir um perímetro mantendo-se na ordem dos $3.331 \mathrm{~m}$. Ressalta-se que, nos últimos anos, constatou-se tendência de aumento do perímetro (maior complexidade no contorno da morfologia dunar). Esta tendência foi possivelmente relacionada às alterações na dinâmica de transporte quando a duna se aproximou da faixa de praia (face de avalanche em contato com as ondas) e as interferências na dinâmica dos ventos pela barreira morfológica provocada pelo serrote de Jericoacoara.

A diminuição da área da DPN (média de $380.562 \mathrm{~m}^{2}$ ) para o mesmo período de registro das imagens de satélite (1975 a 2010), foi definida na ordem de aproximadamente $61.100 \mathrm{~m}^{2}$. Neste período foi possível identificar uma diminuição no perímetro na ordem de aproximadamente $663 \mathrm{~m}$ (tendência de manutenção da morfologia barcanóide). Nos últimos anos, possivelmente desde 2001, constatou-se tendência de manutenção regular do seu perímetro, com uma média de $3.373 \mathrm{~m}$.

A área da duna Arraia (DA), no período de 1975 a 2010, passou por uma diminuição na ordem de aproximadamente $71.454,5 \mathrm{~m} 2$. Neste mesmo período foi possível identificar um aumento no perímetro na ordem de aproximadamente 193,5m (menor valor) - denotando contornos morfológicos bem definidos - diante da duna com maiores área e perímetro da planície costeira (área media aproximada de $419.050 \mathrm{~m} 2$ ).

A diminuição das áreas das dunas estudadas foi associada à disseminação de sedimentos pela ação dos ventos e das ondas, no caso da DPDS. Os ventos promoveram o deslocamento das dunas, mas também atuaram na retirada de areia dos corpos dunares, principalmente no segundo semestre, quando ocorrem as maiores velocidades dos ventos (media de $8 \mathrm{~m} / \mathrm{s}$ de acordo com a ANEEL, 2006) e menores índices de precipitação pluviométrica.

A movimentação da DPDS, desde ao sul do serrote de Jericoacoara, foi de aproximadamente $12 \mathrm{~m} /$ ano, com deslocamento total de aproximadamente $350 \mathrm{~m}$ entre 1975 e 2010 (Figura 12). Entretanto, para o período 2005 a 2010 o deslocamento médio total foi de 50m, com média anual aproximada de $10 \mathrm{~m} /$ ano, registrando uma diminuição relativa na migração do corpo dunar. A DPN apresentou uma velocidade média de migração mais elevada que a DPDS, atingindo uma média de $16 \mathrm{~m}$ de deslocamento por ano (deslocamento total de 470m) (Figura 13). Foi possível verificar aumento no ritmo de deslocamento desta duna nos últimos 5 anos: média de $22 \mathrm{~m} /$ ano (deslocamento total de 110m). 


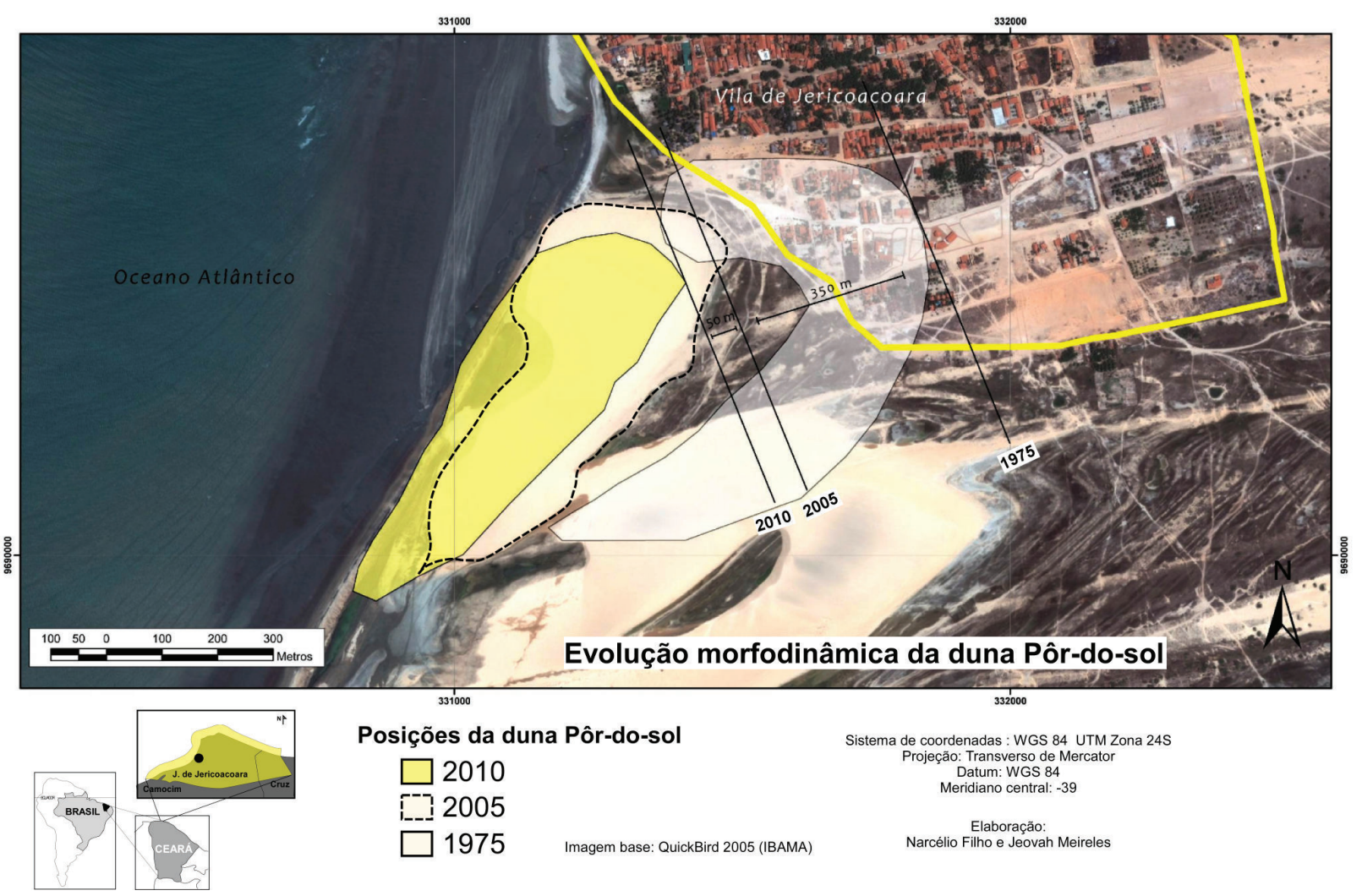

Figura 12 - Deslocamentos definidos para a DPDS através das imagens de satélite (Imagem: QuikBird de 2005).

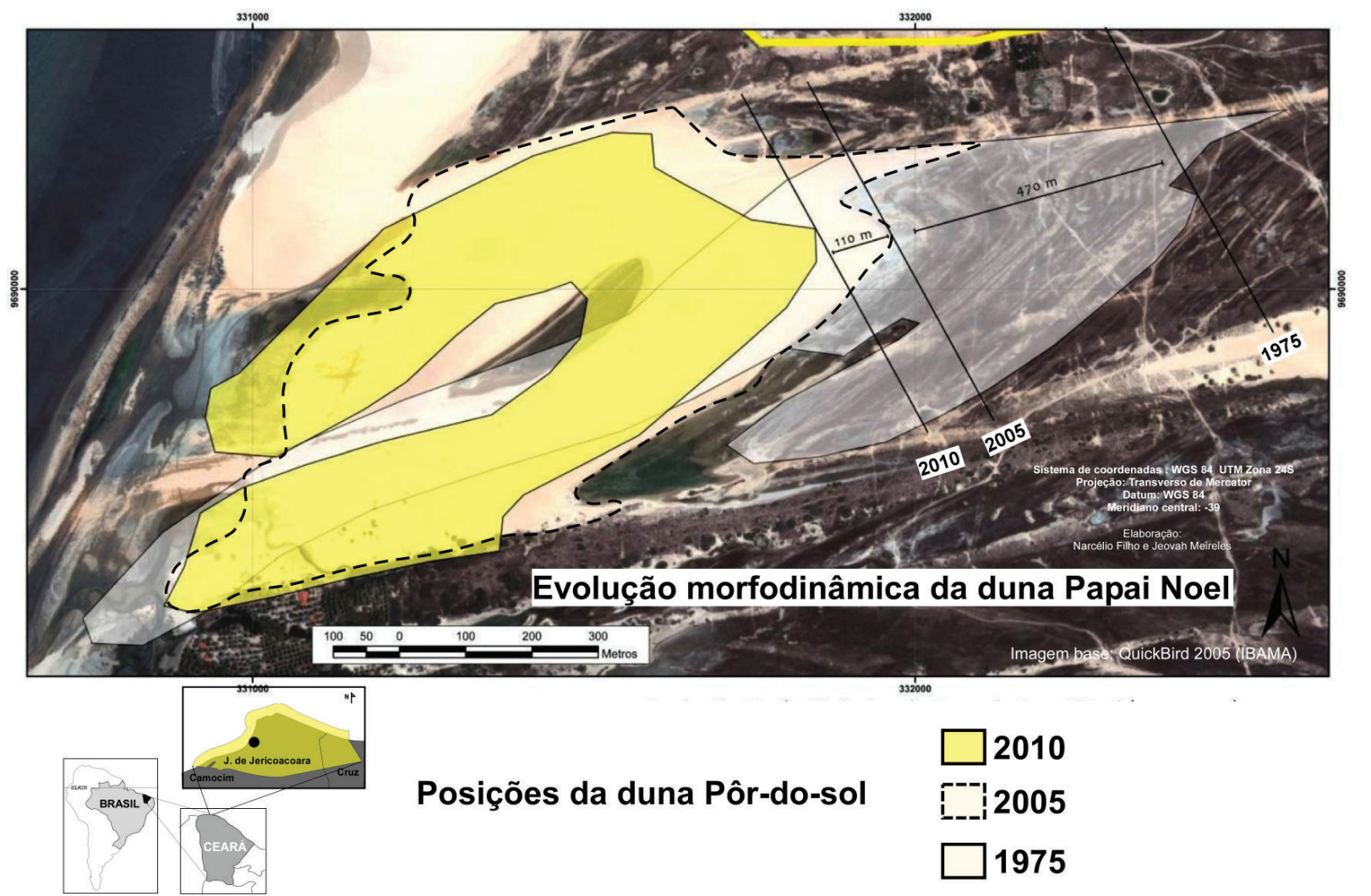

Figura 13 - Deslocamentos definidos para a DPN através das imagens de satélite (Imagem: QuikBird de 2005). 
A duna Arraia movimentou-se também pelo promontório de Jericoacoara e mais ao sudeste das dunas anteriores (Figura 14). Também foi constatado um comportamento diferenciado na velocidade de deslocamento nos últimos 5 anos - com média de $30 \mathrm{~m}$ por ano com deslocamento total de $150 \mathrm{~m}$ - com a maior média de velocidade para as dunas analisadas. Para o período de 30 anos, entre 1975 e 2005 , com um deslocamento de aproximadamente $320 \mathrm{~m}$, definiu-se uma velocidade média de 10,6m por ano, a menor velocidade média em relação ás outras dunas analisadas.

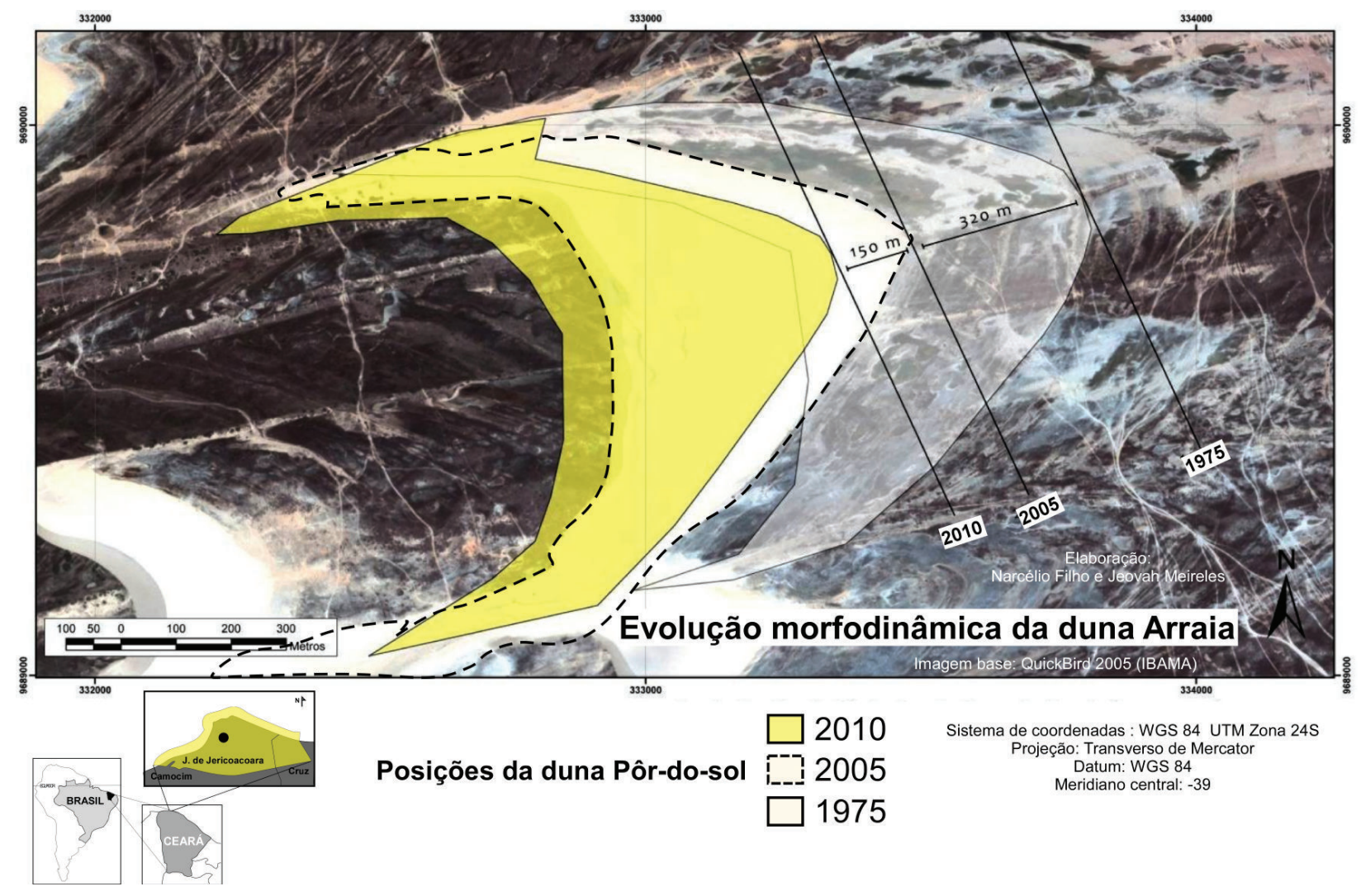

Figura 14- Deslocamentos definidos para a DA através das imagens de satélite (Imagem: QuikBird de 2005).

Provavelmente, com o incremento do turismo, principalmente quando instituída a Unidade de Proteção Integral (a partir de 2000) ocorreu aumento no acesso de visitantes à DPDS, diariamente frequentada por um elevado número de pessoas que sobem até a face de avalanche. Verificou-se incremento no processo de deslizamento dos sedimentos por gravidade, quando os visitantes descem a duna, provocando alterações significativas na morfologia.

Os resultados médios referentes aos dados de área, perímetro e velocidade de deslocamento das dunas (Tabela 2) proporcionaram os primeiros dados médios em intervalos temporais mais amplos e através das informações provenientes de imagens de satélite. A tendência de aumento da velocidade média de migração das dunas nos últimos 5 anos pode estar relacionada com o período de intensificação do acesso de turistas (MEIRELES, et al, 2011). Com a sistematização dos dados relacionados com a velocidade média dos ventos e sazonalidade climática, possivelmente poderão ser associados com eventos mais regionais e globais, como os relacionados com as mudanças climáticas evidenciadas pelo IPCC (2007).

O promontório (serrote de Jericoacoara) certamente influenciou na dinâmica dos ventos e, consequentemente, no transporte de sedimentos e velocidade de deslocamento das dunas (Figura 15). As mais próximas da faixa de praia e do serrote, apresentaram os menores valores médios de migração. Salienta-se que, mudanças bruscas no contorno e tipo de linha de costa (promontórios, falésias, deltas, por exemplo), promovem nova composição de ondas e direção local dos ventos, 
imprimindo um transporte particular nesta faixa do litoral, originando barras longitudinais, bancos e esporões arenosos na zona de estirâncio e antepraia e interferindo no fluxo eólico de transporte de areia. Estas morfologias e a ação das ondas e marés foram detalhadamente estudadas por Mclachlan e Burns (1992) e Carter et al. (1997).

Tabela 2: Resultados médios de área, perímetro e deslocamento das dunas estudadas

\begin{tabular}{c|c|c|c|c} 
DUNAS & $\begin{array}{c}\text { ÁREA MÉDIA } \\
\left(\mathbf{M}^{2}\right)\end{array}$ & $\begin{array}{c}\text { PERÍMETRO } \\
\text { MÉDIO (M) }\end{array}$ & $\begin{array}{c}\text { DESLOCAMENTO } \\
(\mathbf{1 9 7 5 - 2 0 0 5 )}\end{array}$ & DESLOCAMENTO \\
\hline DPDS & 198.472 & 3.331 & $12,0 \mathrm{~m}$ & $10,0 \mathrm{~m}$ \\
\hline DPN & 380.562 & 3.373 & $15,6 \mathrm{~m}$ & $22,0 \mathrm{~m}$ \\
\hline DA & 419.050 & 3.372 & $10.6 \mathrm{~m}$ & $30,0 \mathrm{~m}$ \\
\hline Médias & 332.695 & 3.359 & $12,4 \mathrm{~m}$ & $20,6 \mathrm{~m}$
\end{tabular}

Fonte: Banco de dados da pesquisa/CNPq.

A flecha de areia diante do manguezal do rio Guriú avançou $1.060 \mathrm{~m}$ na direção da margem direita do rio, de acordo com chegada de sedimentos proveniente da deriva litorânea (Figura 16). Trata-se, inicialmente, de um indicador atual de que possivelmente o canal estuarino foi fechado por fechas de areia e campos de dunas. Eventos que provocaram mudanças ambientais que certamente evoluíram para laguna e lagoa costeira (a exemplo da lagoa do Catú, entre outras, no litoral leste do Ceará). Durante eventos de máxima vazão fluvial, o fluxo hidráulico rompeu os depósitos de areia diante da desembocadura, reabilitando as reações ambientais que orientaram o sistema a evoluir na direção do ecossistema manguezal atual. Ressalta-se ainda que, ao ser definida erosão da flecha de areia em aproximadamente 50m - entre 1988 e 2008, caso o avanço médio tenha se mantido para os últimos 20 anos -, demonstrou-se efeitos erosivos em áreas de aporte de areia, notadamente associadas à progradação da linha de praia mar adentro. 

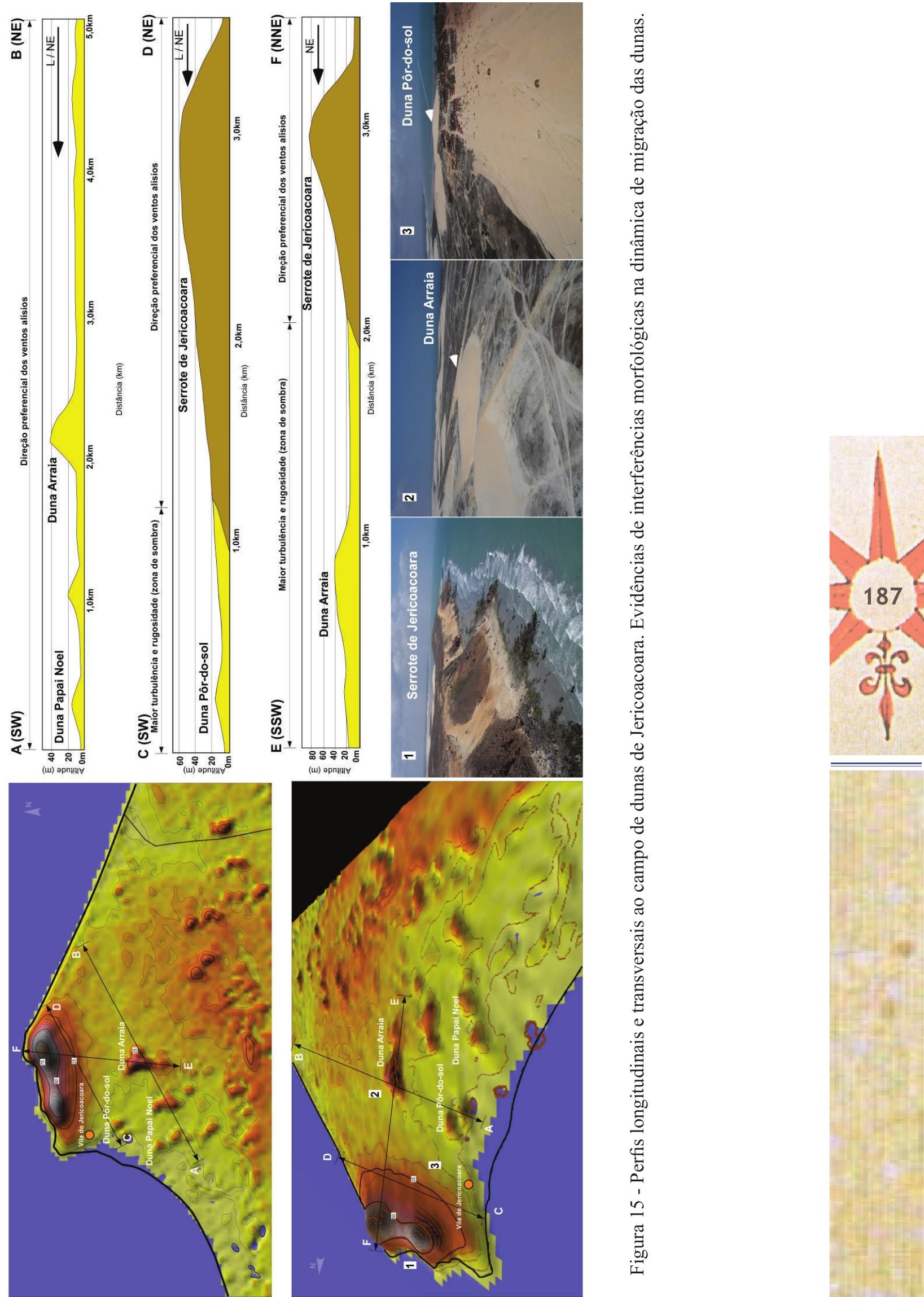

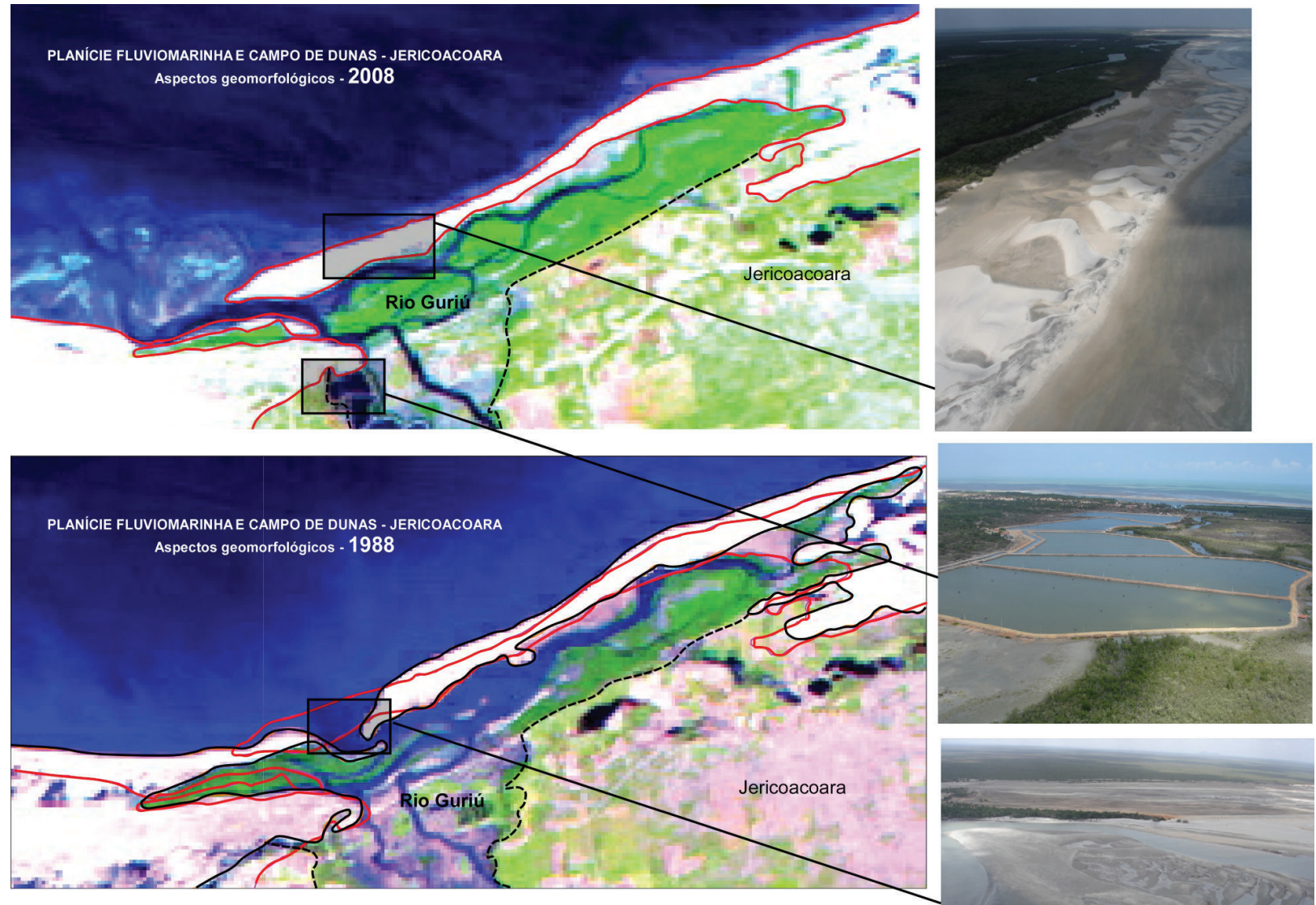

188

$4 \mathbf{N}$
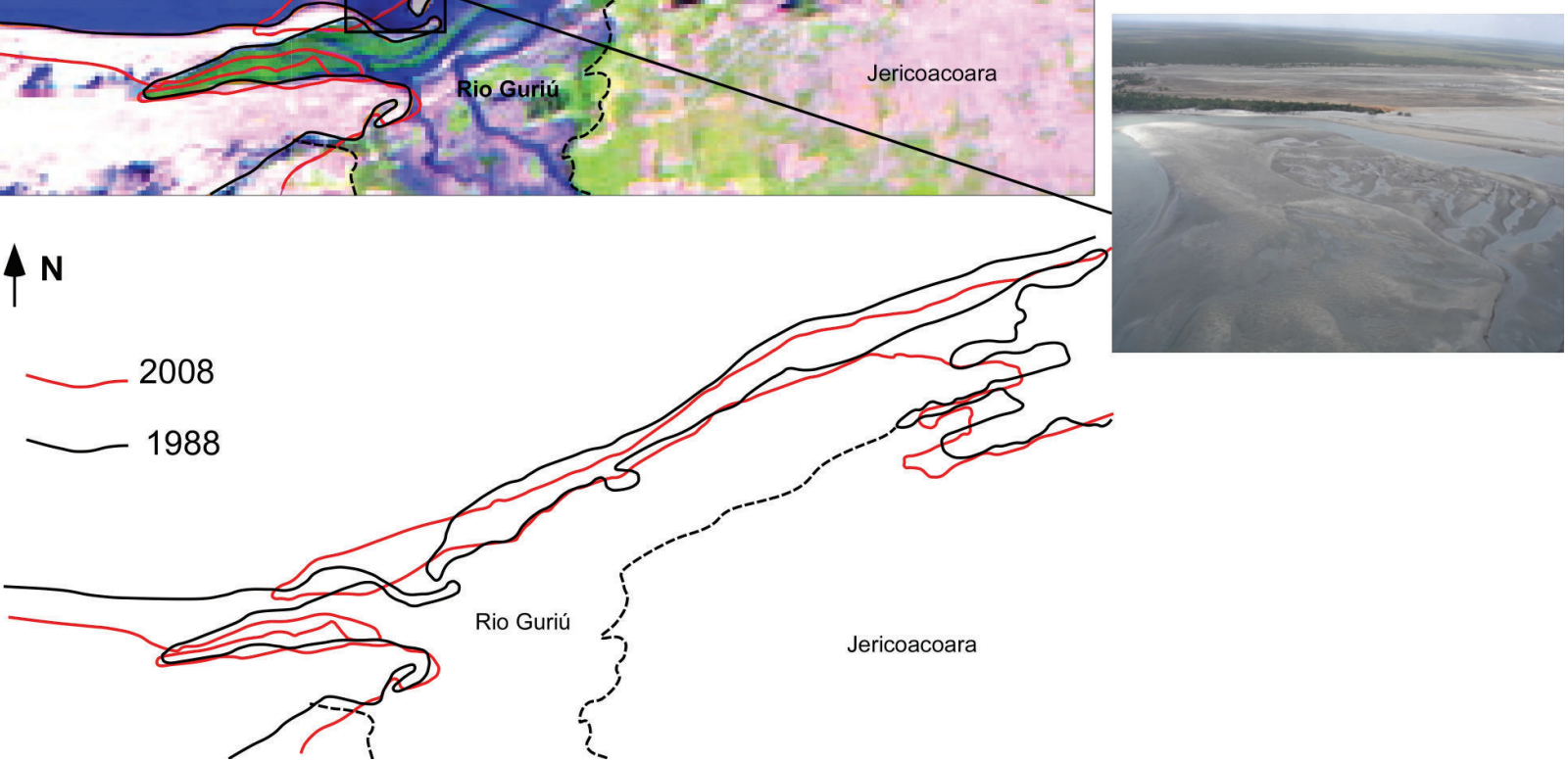

Figura 16 - Evolução das dunas e flecha de areia diante do ecossistema manguezal do rio Guriú, limite oeste do Parna de Jericoacoara.

\section{CONSIDERAÇÕES FINAIS}

A utilização das técnicas de geoprocessamento para a o mapeamento da evolução morfodinâmica do campo de dunas do Parque Nacional de Jericoacoara constituiu-se uma ferramenta essencial para a produção de informações que certamente irão subsidiar a continuidade do planejamento ambiental da referida UC de Proteção Integral. Isso devido ter sido configurada a dinâmica espacial e evolução do processo de deslocamento das dunas móveis. Foram caracterizados os componentes ambientais de um conjunto morfológico costeiro relacionado com os setores de transpasse de sedimentos para o litoral (by-pass de areia).

Através da comparação de imagens entre o período de 1975 a 2010, foi possível constatar mudanças significativas nos aspectos fisiográficos - área e perímetro - do campo de dunas inserido 
no Parna de Jericoacoara. As mudanças foram mais significativas, sobretudo, nos anos de 2001 a 2005, o que podem estar relacionadas a uma maior intervenção humana (fluxo de turistas). O incremento do tráfego de veículos com a origem de trilhas aleatórias para acessar a vila de Jericoacoara, degradação da vegetação fixadora dos sedimentos, compactação do solo, reativação do transporte de areia e maior número de pessoas caminhando sobre as dunas móveis (principalmente a DPDS).

Os resultados alcançados evidenciaram necessidade de ampliar a investigação com e definição de alterações setoriais na temperatura da água do mar, relacionadas às teleconexões continente-oceano-atmosfera com as altas latitudes (BROECKER, 2001). As dunas de Jericoacoara, relacionadas como indicadoras de mudanças de alta frequência do nível relativo do mar, podem estar vinculadas a alterações abruptas e cíclicas nas temperaturas dos oceanos e sobreimpostas a ciclos orbitais maiores (ciclos Dansgaard-Oeschger, evento frio Younger Dryas; CACHO, et al. 1999 e MORENO, et al. 2002).

Os resultados alcançados auxiliaram na compreensão da dinâmica costeira e nas interferências provocadas pelo incremento da atividade turística. Desta forma, deverão ser ampliados através de estudos associados à dinâmica regional e global dos componentes meteorológicos, enfocando possíveis interferências das mudanças climáticas na evolução das dunas costeiras. Foram também fundamentais para efetivar planos quantitativos de monitoramento das dunas, através da utilização de imagens multitemporais de satélite.

\section{REFERÊNCIA BIBLIOGRÁFICA}

ALVES, J.M.B.; COSTA, A.A.; SOMBRA, S.S.; CAMPOS, J.N.B.; SOUZA FILHO, F.A., de; MARTINS, E.S.P.R., MARIANO DA SILVA, E.; SANTOS, A.C.S. dos; BARBOSA, H.A. MELCIADES, W.L.B. e MONCUNNIL, D.F. Um estudo inter-comparativo de previsão sazonal estatística- dinâmica de precipitação no nordeste do Brasil. Revista Brasileira de Meteorologia, São Paulo, vol.22, n 3, 2007, p. 354-372. ANNEL. Agência Nacional de Energia Elétrica. Relatórios 2003 e 2006. Obtidos através de www.aneel. gov.br/15.htm [consulta realizada 17 abril de 2010]

ARRUDA, M. G. C. Parque Nacional de Jericoacoara: Zoneamento para Gestão e Uso Público. Dissertação (Mestrado em Geografia). Departamento de Geografia. Universidade Federal do Ceará, Programa de Pós-graduação em Geografia da UFC, Fortaleza, (2007) 132p.

BRASIL. Capacidade de geração do Brasil. Disponível em: $<$ http://www.aneel.gov.br/aplicacoes/capacidadebrasil/capacidadebrasil.asp>.2009a. Acesso em: 23 mai. 2011.

BROECKER, W. S. Was the medieval warm period global? Science, 291, 2001, 1497-1499

CACHO, I., GRIMALT, J. O., PELEJERO, C., CANALS, M., SIERRO, F. J., FLORES, J. A., e SHACKLETON, N. J. Dansgaard-Oeschger and Heinrich event imprints in Alboran Sea temperatures. Paleoceanography 14, 1999, 698-705.

CARTER, R.W.G.; HESP, P.A. and NODSTROM, K.F. Erosional lanforms in coastal dunes. Ed. by Nordstrom, K.F.; Psuty, N. \& Carter. Bill. Coastal dune - from and process. 1997. p. 217- 250.

FUNCEME Fundação Cearense de Meteorologia e Recursos Naturais - Governo do Estado do Ceará. Relatórios internos e boletins, Fortaleza/Ceará, 2011. www.funceme.br [consulta realizada 13 junho de 2011]. IPCC. Cambio climático 2007: Informe de síntesis. Contribución de los Grupos de trabajo I, II y III al Cuarto Informe de evaluación del Grupo Intergubernamental de Expertos sobre el Cambio Climático [Equipo de redacción principal: Pachauri, R.K. y Reisinger, A. (directores de la publicación)]. IPCC, Ginebra, Suiza, 2007, 104 págs. Consultado em 22 de fevereiro de 2010. URL: http://www.ipcc.ch/pdf/ assessment-report/ar4/syr/ar4_syr_sp.pdf

IPECE. Instituto de Pesquisa e Estratégia Econômica do Ceará. Perfil básico municipal - Jijoca de Jericoacoara, $201016 \mathrm{p}$.

KOCUREK, G and EWING, R.C. Aeolian dune field self-organization - implications for the formation of simple versus complex dune-field patterns. Geomorphology vol. 72, (2005), p.94-105. 
MARTIN, L.; BITTENCOURT, A.C.S.P.; VILAS-BOAS, G.S. Principais ocorrências de corais pleistocênicos da costa brasileira. Datação do máximo da última transgressão. Ciência da terra, vol. 1, (1982), p.16-17. MCLACHLAN, A and BURNS, M. Headland bypass dunes on the South African coast: 100 yars of (mis)management. Coastal dunes, Carter, Curtis \& Sheehy-Skeffington (eds); Belkema, Rotterdam. 1992. p.71-79. MEIRELES, A. J. A.; ARRUDA, M.C; GORAYEBE, A. e THIERS, P.R.L . Integração dos indicadores geoambientais de flutuação do nível relativo do mar e de mudanças climáticas no litoral cearense. Revista Mercator, vol. 8, 2005, p. 109-134.

MEIRELES, A.J.A. e MORAIS, J.O. Compartimentação geológica, processos dinâmicos e uso e ocupação da Planície Costeira de Parajuru, município de Beberibe, litoral leste do Estado do Ceará. Revista de Geologia, Fortaleza, vol. 7, 1994, p.69-81.

MEIRELES, A.J.A. e RÚBIO, P.R. Geomorfología litoral: una propuesta metodológica sistémica en la llanura costera de Ceará, nordeste de Brasil. Revista de Geografia, Universitat de Barcelona, España; vol. 32/33, 1999. p.165-182.

MEIRELES, A.J.A. e SERRA i RAVENTOS, J. Um modelo Geomorfológico Integrado para a Planície Costeira de Jericoacoara/CE. Revista Mercator, Fortaleza, vol. 1, 2002. p. 79-92.

MEIRELES, A.J.A. Impactos ambientais decorrentes da ocupação de áreas reguladoras do aporte de areia: a planície Costeira da Caponga, município de Cascavel, litoral leste cearense. Confins, Número 2 / Numéro 2, $1^{\circ}$ semestre $2008 / 1$ er semestre 2008, [En ligne], mis en ligne le 13 mars 2008. URL : http://confins. revues.org/document2423.html. Consulta em 19 de maio de 2011.

MEIRELES, A.J.A; SILVA, E.V. e THIERS, P.R.L. Os campos de dunas móveis: fundamentos dinâmicos para um modelo integrado de planejamento e gestão da zona costeira. Revista Geousp - Espaço e Tempo, São Paulo, n 20, 2006. p.101 - 119.

MEIRELES, AJA., DANTAS, E.W.C. e VICENTE DA SILVA, E. Planície costeira de Jericoacoara: nas trilhas da sustentabilidade. Edições UFC, Fortaleza, 2011. 125p.

MORENO, A., CACHO, I., CANALS, M., PRINS, M. A., SÁNCHEZ-GOÑI, M. F., GRIMALT, J. O., e WELTJE, G. J. Saharan dust transport and high latitude glacial climatic variability: the Alboran Sea record. Quaternary Research n58, 2002, p.318-328.

PIRAZZOLI, P.A. Sea-level changes. The last 20.000 years. Wiley, Chichester, 1996. 211p,.

PRISKIN, J. Physical impacts of four-wheel drive related tourism and recreation in a semi-arid, natural coastal environment. Ocean \& Coastal Management, vol. 46, $n^{\circ}(1-2), 2003$, p. 127-55.

RODRIGUES, M. A. Conceitos básicos de sistemas de informações geoambientais e áreas de aplicação em cadastro técnico municipal. In.: XV Cong. de Cartografia. Anais..., São Paulo, vol. 3, 1991, p. 542-546.

RODRIGUEZ, J. M. M., VICENTE DA SILVA, E. CAVALCANTI, A. P. B, Geoecologia das Paisagens: Uma Visão Geossistêmica da Análise Ambiental. Fortaleza: Editora UFC, 2004.

SHACKLETON, N.J. Oxigen isotope, ice and sea-level. Quaternary Science Reviews, vol 6., 1987, p. 183-190.

SOTCHAVA, V. B. O estudo dos geossistemas. São Paulo: USP, 48p. (Traduzido da versão inglesa The Study of Geossystems), (1977).

STEINBACK, J. Study of Cape Cod Seashore Finds Off-road Vehicles Harmful To Beach Fauna. University Of Rhode Isla. http://www.sciencedaily.com/releases/, 2004 [consulta realizada 22 fevereiro de 2011]. STEPHENSON, G. Vehicle impacts on the biota of sandy beaches and coastal dunes. A review from a New Zealand perspective, Science For Conservation 121, 1999. 48p.

SUNAMURA, T. Geomorphology of rock coast. $1^{\text {a }}$ Ed.; University of Tsukuba, Japan: 1994. 301p.

TEIXEIRA, A. L. de A. et. al. Introdução aos Sistemas de Informação Geográfica. Rio Claro: Edição do autor, 80p., 1992.

Trabalho enviado em junho de 2011

Trabalho aceito em agosto de 2011 